\title{
Probabilistic analysis of weld cracks in center-cracked tension specimens
}

\author{
Mark Francis $^{\mathrm{a}}$, Sharif Rahman ${ }^{\mathrm{b}, *}$ \\ ${ }^{a}$ Hibbitt, Karlsson and Sorensen, Inc., Plymouth, MI 48170, USA \\ ${ }^{\mathrm{b}}$ Department of Mechanical Engineering, The University of Iowa, Iowa City, IA 52242, USA
}

Received 1 September 1998; accepted 3 June 1999

\begin{abstract}
This paper describes the development of a probabilistic methodology for fracture-mechanics analysis of weld cracks in a center-cracked tension (CCT) specimen. It involves elastic-plastic analyses to predict $J$-integral, statistical models of uncertainties in loads and material properties, and standard computational methods of structural reliability theory for probabilistic analysis. Eighty-one deterministic finite element analyses were performed for a wide variety of crack size, material mismatch factors, and weld geometric parameters to develop approximate equations for the $J$-integral of a CCT specimen and were subsequently applied for probabilistic fracture evaluations. Both fast probability integrators, such as first- and second-order reliability methods, and Monte Carlo simulation were used to determine the probabilistic characteristics of the $J$-integral. The same methods were used later to predict the failure probability based on initiation of crack growth. Numerical results are presented to illustrate the proposed methodology. The effects of mismatch factors on both deterministic and probabilistic response characteristics were examined. The results indicate that the tensile properties of both base and weld materials should be accounted for when calculating $J$. These mismatch factors have a significant effect on the probabilistic characteristics of $J$ and failure probability. (C) 2000 Elsevier Science Ltd. All rights reserved.
\end{abstract}

Keywords: Elastic-plastic fracture mechanics; Weld cracks; Probabilistic fracture mechanics; $J$-integral; Probability of failure; Base metal; Weld metal; Mismatch factors

\section{Introduction}

When a crack is located in or near welds, a dissimilar material interface is present near the crack. In assessing the integrity of structures containing such cracks, it is important to quantify the relevant crackdriving force so that its load-carrying capacity can be

\footnotetext{
* Corresponding author. Tel.: + 1-319-335-5679; fax: +1319-335-5669.

E-mail address: rahman@icaen.uiowa.edu (S. Rahman).
}

predicted. For ductile materials permitting large-scale plasticity near the crack tip, this crack-driving force is frequently described in terms of the $J$-integral, which is an appropriate elastic-plastic fracture parameter (in absence of constraint effects) for low-strength and high-toughness materials. However, when a crack is in the vicinity of a weld, the calculation of $J$ becomes much more complex, because the material near a weld and crack is inhomogeneous as regards its tensile strength property [1]. There are weld material, heataffected zone (HAZ) material, and base (parent) material with mismatched stress-strain curves. Conse- 
quently, the fracture behavior cannot be accurately determined by an analysis involving all-base, all-HAZ, or all-weld material properties alone. It should involve the characteristics of base, HAZ, and weld materials, the weld and crack geometry relative to the size of structure, and possibly residual stresses induced by the multi-layer welding process $[2,3]$.

The evaluation of $J$-integral for cracked welded structures is usually performed by: (1) numerical analysis and (2) engineering estimation techniques. Traditionally, a numerical study has been based on the elastic-plastic finite element method (FEM). Using the FEM, one can simulate various weld and crack geometries and mismatching variables. However, it is also useful to have simplified estimation methods for routine engineering calculations. Most $J$-estimation methods, which are currently available today, are based on mathematical formulations derived for homogeneous materials and hence, can account for strength properties of either base or weld metal explicitly. Predictions are usually made using the base-metal stressstrain curve and the weld-metal $J$-resistance $(J-R)$ curve [4-6]. This can lead to mispredictions depending on the strength ratio of the base versus weld material. Hence, to improve the accuracy of fracture response and load predictions, a number of recent studies on weld cracks have also appeared. For two-dimensional weld-crack problems involving center-cracked tension (CCT) and single-edged notched bend specimens, approximate methods have been developed or examined by Gilles and Franco [7], Eripret and Hornet [8], Hornet and Eripret [9], Joch et al., [10], Wang and Kirk [11], and Lei and Ainsworth [12,13]. They are based on limit-load analysis and the concept of an equivalent homogeneous material. Some of these studies also involve a limited number of finite element analysis (FEA) to verify the $J$-estimation methods. A distinctly different approach was taken by Yagawa et al. [14], who proposed a rule of mixture for material properties that can be applied for analyzing welded structures using standard $J$-estimation methods for homogeneous materials. The optimum ratio of this mixture for material constants is obtained by an inverse analysis procedure based on neural network techniques. So far, this approach has been applied to small fracture specimens with a reasonable amount of success. In addition to the $J$-estimation methods, other studies involving various analytical, computational, and experimental work on elastic-plastic analysis of inhomogeneous materials and structures have also been reported [14].

For three-dimensional weld-crack problems, methods have also been developed with particular attention to through-wall-cracked (TWC) pipe welds [4-6,15-19]. For example, an empirical approach, proposed by Ganta and Ayres [16], suggests that the load-carrying capacity of a cracked welded pipe can be evaluated by applying a multiplicative correction factor on the load predicted by assuming a base-metal stress-strain curve and a weld-metal $J-R$ curve. The correction factor involves a power-law function of the yield ratio of weld and base metals and requires two empirical parameters for its evaluation. Recently, a method was also developed by Rahman and Brust [17-19] to determine $J$-integral and crack-opening displacement for a TWC pipe weld that includes strength properties of both base and weld metals. The method is based on an equivalence criterion incorporating a reduced thickness analogy for simulating system compliance due to the presence of a crack in a pipe. The results from this method suggest that the values of $J$ for a pipe weld can be overpredicted or underpredicted if the material stress-strain curve is represented by all-base or all-weld properties alone. It was also shown that if the material properties of both base and weld metals are taken into account, the estimated $J$ values became much closer to the more accurate finite element solutions. Later, Rahman et al. [5,6] showed that this method also predicts a more accurate load-carrying capacity of stainless steel flux welds when compared with test data generated from full-scale pipe fracture experiments [4]. In spite of all these studies, the methods in existence today are limited to strictly deterministic analyses. Due to inherent statistical variabilities in loads, material properties, and geometric parameters, a probabilistic methodology is needed to evaluate the stochastic characteristics of fracture response and reliability of welded structures. Hence, a probabilistic study on weld cracks and an investigation on how the weld and material parameters affect structural reliability is timely and exciting.

This paper presents a probabilistic methodology for fracture-mechanics analysis of weld cracks in a CCT specimen. It is based on: (1) elastic-plastic analyses to calculate $J$-integrals by ABAQUS finite-element code [20], (2) statistical models of uncertainties in loads and material properties, and (3) standard computational methods of structural reliability theory for probabilistic analysis. Eighty-one deterministic FEA were performed for a wide variety of crack sizes, material mismatch factors, and weld geometric parameters to develop approximate equations for the $J$-integral of a CCT specimen and were subsequently applied for probabilistic analysis. Both fast probability integrators, such as first- and second-order reliability methods (FORM/ SORM) and Monte Carlo simulation (MCS) were used to determine the probabilistic characteristics of the $J$ integral. The same methods were used later to predict the failure probability based on initiation of crack growth. Numerical results are presented to illustrate the proposed methodology. 


\section{Elastic-plastic fracture mechanics}

The $J$-integral fracture parameter proposed by Rice [21] has been extensively used in assessing fracture integrity of cracked engineering structures, which undergo large plastic deformation. For elastic-plastic problems, its interpretation as the strength of the asymptotic crack-tip fields by Hutchinson [22] and Rice and Rosengren [23] represents the crux of the basis for ' $J$-controlled' crack growth behavior. For a cracked body with an arbitrary counter-clockwise path $\Gamma$ around the crack tip, a formal definition of $J$-integral under the mode-I condition is

$J \stackrel{\text { def }}{=} \int_{\Gamma}\left(\mathscr{W} n_{1}-T_{i} u_{i, 1}\right) \mathrm{d} \Gamma$

where $\mathscr{W}=\int \sigma_{i j} \mathrm{~d} \varepsilon_{i j}$ is the strain energy density with $\sigma_{i j}$ and $\varepsilon_{i j}$ representing components of stress and strain tensors, respectively, $u_{i}$ and $T_{i}=\sigma_{i j} n_{j}$ are the $i$ th component of displacement and traction vectors, $n_{j}$ is the $j$ th component of unit outward normal to integration path, $\mathrm{d} \Gamma$ is the differential length along contour $\Gamma$, and $u_{i, 1}=\partial u_{i} / \partial x_{1}$ is the differentiation of displacement with respect to $x_{1}$. Here, the summation convention is adopted for repeated indices.

The $J$-integral is theoretically valid for nonlinear elasticity or deformation theory of plasticity where no or little unloading occurs. It is frequently used to characterize the initiation of crack growth and a small amount of crack propagation. In the case of large amounts of crack growth, a great deal of unloading occurs around the crack tip and hence, $J$ may lose its theoretical validity because of path dependence. In such a condition, more advanced fracture parameters, such as the $T^{*}$-integral [24] and the $\hat{J}$-integral [25] which hold path independence during crack growth, should be used. However, a wealth of comparisons between predictions based on $J$-integral versus experimental data now show that fairly accurate results can be obtained for monotonic loading to failure even though the theoretical conditions for a valid $J$-based fracture theory are violated [26-33]. In this study, the analysis of welds will focus only on the $J$-integral fracture parameter.

For monotonically loaded elastic-plastic structures, the $J$-integral completely describes the crack-tip condition. The philosophy of using $J$ to characterize elastic-plastic crack growth, as lucidly summarized by Hutchinson [34], may be mathematically stated as:

Crack Initiation: $\quad J=J_{\text {Ic }}$

Crack Instability: $\left\{\begin{array}{l}J=J_{\mathrm{R}} \\ \frac{\partial J}{\partial a}=\frac{\mathrm{d} J_{\mathrm{R}}}{\mathrm{d} a}\end{array}\right.$
The left sides of Eqs. (2) and (3) represent the crack driving force and its rate while $J_{\mathrm{Ic}}$ and $J_{\mathrm{R}}$, representing the fracture toughness at crack initiation and crack growth, $\mathrm{d} a$, respectively, are the crack resistance property of the material. If one can calculate $J$ for a given cracked structure, the corresponding values of loads for crack initiation and fracture instability can be predicted from the known $J-R$ curve of the material. Note, the $J-R$ curve, which is typically generated from small-scale laboratory specimens, must be prescribed in such a way that similar constraint conditions exist in both cracked structure and laboratory specimens. Otherwise, constraint effects should be accounted for in the fracture-mechanics analysis $[5,6]$.

\section{The CCT weld crack problem}

Consider Fig. 1, which illustrates a CCT specimen subjected to a far-field tensile stress, $\sigma^{\infty}$ applied at the

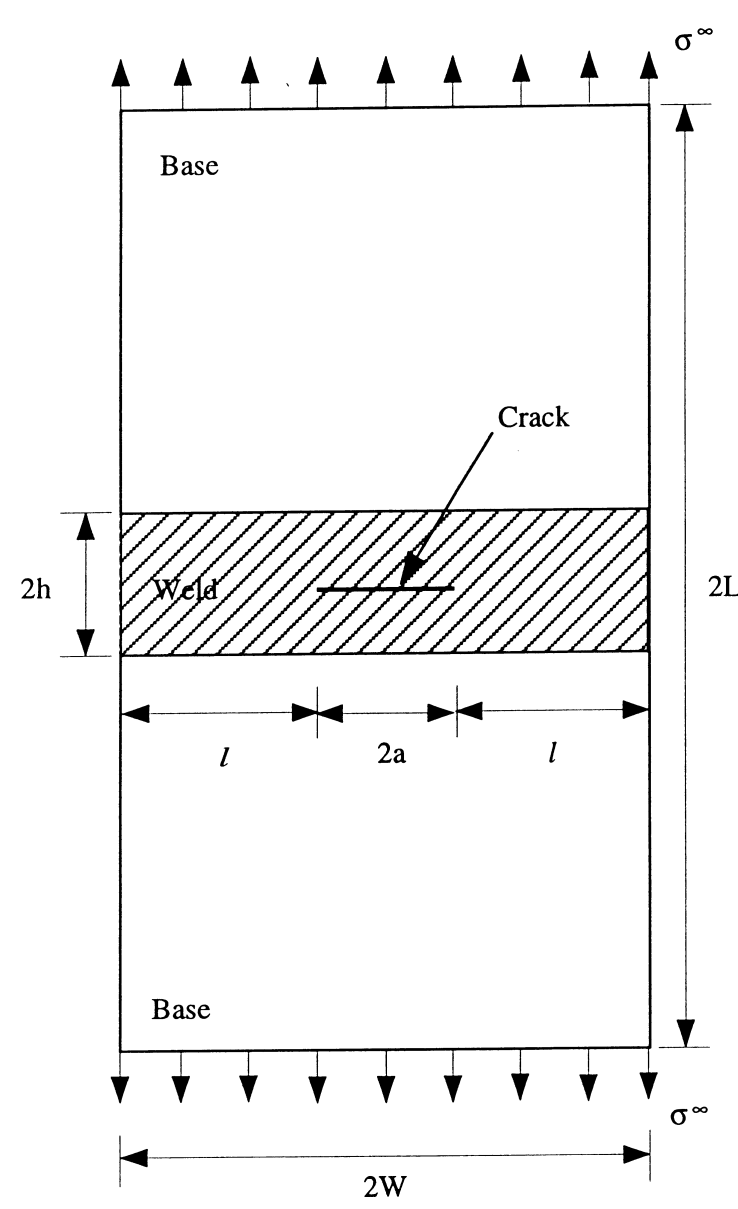

Fig. 1. Schematics of a center-cracked tension specimen with all geometric parameters. 
remote ends. The specimen has length, $2 L$, width, $2 W$, and a center-crack of length, $2 a$. The crack is located inside the weld material which has width, $2 h$. The length of the uncracked ligament is defined as $2 l$, where, $l=W-a$. To study its elastic-plastic behavior, the following simplifying assumptions were made:

1. The crack is two-dimensional with mode-I loading and the state of stress is characterized by plane strain condition.

2. Only base and weld metals are considered to represent the material inhomogeneity. Hence, there is a sudden transition between weld and base materials and their mechanical properties. No HAZ material is considered.

3. The elastic properties of base and weld materials are the same (i.e., same elastic modulus, $E$, and Poisson's ratio, $v$ ). This assumption is supported by experimental data [26-33]. The uniaxial stress-strain curves for the base or weld materials follow the Ramberg-Osgood equation:

$\frac{\varepsilon}{\varepsilon_{0 k}}=\frac{\sigma}{\sigma_{0 k}}+\alpha_{k}\left(\frac{\sigma}{\sigma_{0 k}}\right)^{n_{k}}$

where, $\sigma_{0 k}$ is a reference stress, which can be arbitrary, but usually assumed to be the yield stress, $\sigma_{y k}, E$ is the modulus of elasticity, $\varepsilon_{0 k}=\sigma_{0 k} / E$ is the associated reference strain, and $\alpha_{k}$ and $n_{k}$ are model parameters usually chosen from a best fit of actual laboratory data, and $k=1$ or 2 representing base or weld materials, respectively. Two mismatch factors given by

$k_{\sigma}=\frac{\sigma_{02}}{\sigma_{01}}$

$k_{n}=\frac{n_{2}}{n_{1}}$

are defined based on material reference stresses and hardening exponents, respectively. They are denoted as the strength mismatch factor and the hardening mismatch factor in this paper.

4. Weld-induced residual stresses are ignored. This is a reasonable assumption when the stresses due to primary loads in a structure are much larger than the residual stresses. Otherwise, residual stresses should be considered, but in that case the $J$-integral defined by Eq. (1) may not be a meaningful fracture parameter due to the loss of path independence.

All of the load and geometric parameters defined above are sketched in Fig. 1.

\section{Deterministic fracture analysis}

The FEM in this study assumes the elastic-plastic
Table 1

CCT geometric parameters for finite element validations ${ }^{\mathrm{a}}$

\begin{tabular}{lllll}
\hline Cases & $L(\mathrm{~mm})$ & $W(\mathrm{~mm})$ & $a(\mathrm{~mm})$ & $h(\mathrm{~mm})$ \\
\hline (a), (c), (e) & 224 & 96 & 48 & 20 \\
(b), (d) & 224 & 96 & 24 & 20 \\
\hline
\end{tabular}

${ }^{a}$ Further details are available in the paper by Lei and Ainsworth [12].

constitutive relation given by Eq. (4) and small strains. It was based on proportional loading in the crack-tip plastic zone. Hence, the use of deformation theory of plasticity and Eq. (4) is entirely appropriate. The plastic deformation was assumed to be incompressible and independent of hydrostatic stress. An isotropic hardening rule was assumed. While the analysis is for small strains, nonlinearity enters through Eq. (4).

For calculating $J$, the domain integral method [3537] was used. This method is implemented into the ABAQUS commercial finite element code (Version 5.6) [20]. The method is quite robust in the sense that accurate $J$-integral estimates are usually obtained even with coarse meshes. This is because the integral is evaluated over a domain of elements surrounding the crack front, so that the errors in local solution parameters have a lesser effect on the value calculated.

\subsection{Verification of calculated $J$ by $A B A Q U S$}

In order to validate the $J$-integral solutions for CCT specimens, a limited number of FEAs were performed initially for which cases there were existing solutions available in the literature. Tables 1 and 2 show the CCT geometric parameters and material properties, respectively, for five cases taken from the past work of Lei and Ainsworth [12]. Using these input data from Tables 1 and 2, several elastic-plastic analyses were conducted to compute $J$ using the ABAQUS finite el-

Table 2

CCT material properties for finite element validations $\mathrm{s}^{\mathrm{a}}$

\begin{tabular}{lllllll}
\hline Cases & \multicolumn{2}{c}{ Base metal } & \multicolumn{5}{c}{ Weld metal } \\
\cline { 2 - 7 } & $\sigma_{01}(\mathrm{MPa})$ & $\alpha_{1}$ & $n_{1}$ & $\sigma_{02}(\mathrm{MPa})$ & $\alpha_{2}$ & $n_{2}$ \\
\hline (a), (b) & 413.68 & 1.12 & 9.71 & 827.36 & 0.56 & 9.71 \\
(c) & 413.68 & 1.12 & 9.71 & 124.1 & 3.73 & 9.71 \\
(d) & 413.68 & 1.12 & 9.71 & 289.58 & 1.60 & 9.71 \\
(e) & 413.68 & 1.12 & 9.71 & 413.68 & 1.12 & 6.00 \\
\hline
\end{tabular}

${ }^{a}$ The elastic properties of both base and weld metals are as follows: $E=207 \mathrm{GPa}, v=0.3$. Further details are available in the paper by Lei and Ainsworth [12]. 


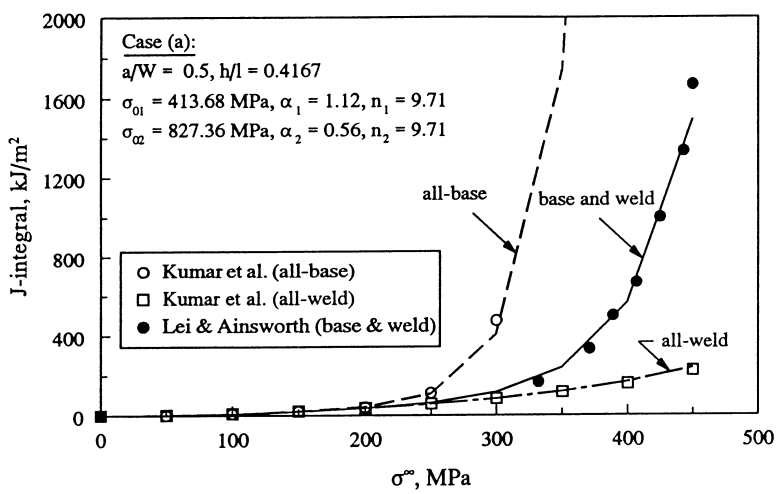

(a) Case (a)

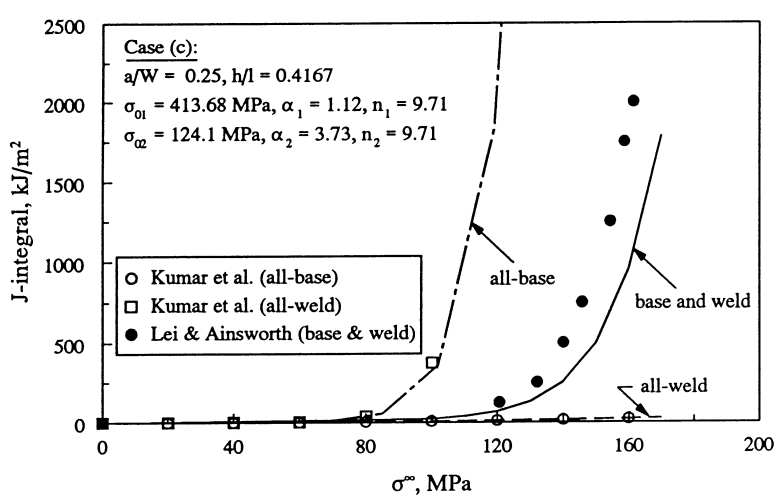

(c) Case (c)

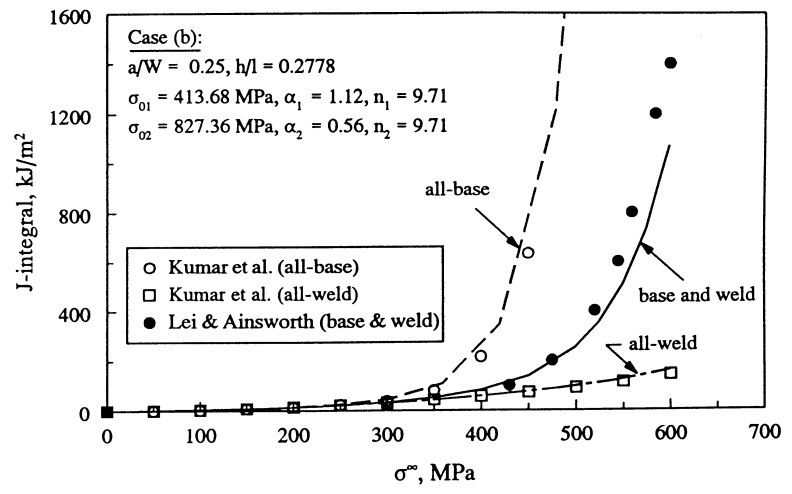

(b) Case (b)

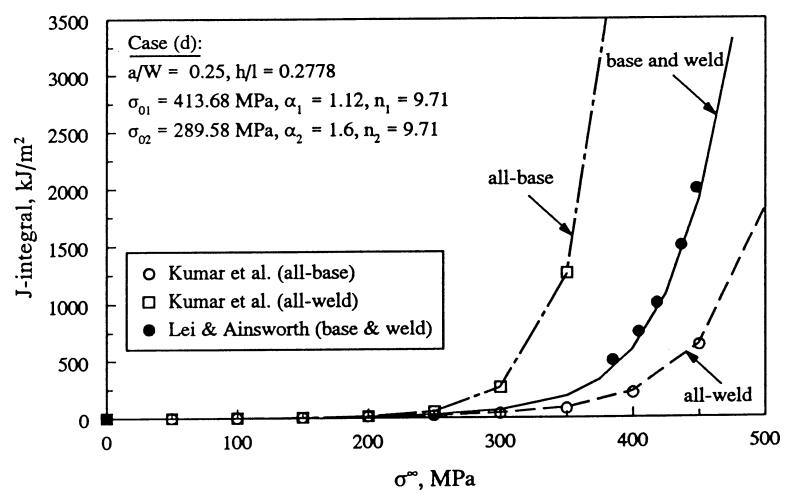

(d) Case (d)

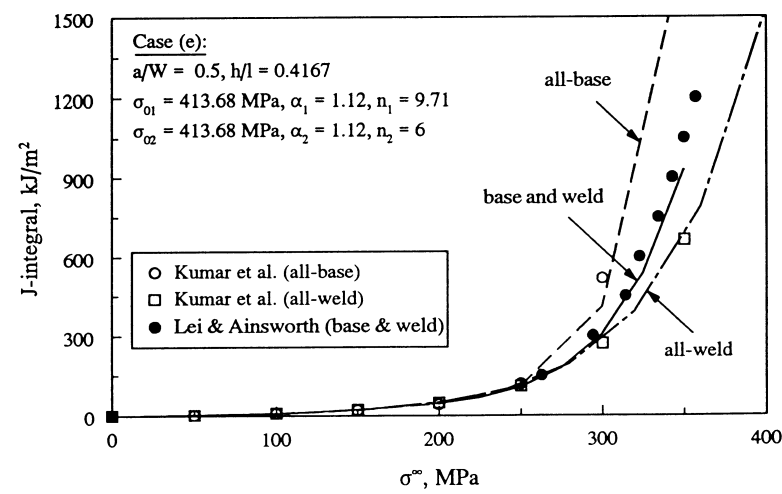

(e) Case (e)

Fig. 2. Comparisons of predicted $J$ for CCT specimens with existing solutions.

ement code. Fig. 2 shows the comparisons of $J$ vs. $\sigma^{\infty}$ plots from the present study (solid lines) with the corresponding finite element results generated by Lei and Ainsworth (closed points) [12]. The two sets of results are in close agreement with each other. Also, plotted in Fig. 2 are the corresponding homogenous solutions (i.e., using all-base and all-weld material properties) by the authors' own FEA (broken lines) and a J-estimation formula developed by Kumar et al. (open points ) [38]. The FEM results are practically identical to the existing solutions. These results gave confidence in our finite element calculations. 


\subsection{Finite element model and analysis matrix}

Following validation of $J, 81$ elastic-plastic FEAs were conducted for the CCT specimen in Fig. 1 with $W=100 \mathrm{~mm}$ and $L=350 \mathrm{~mm}$. A matrix of such analyses is defined in Table 3 for various combinations of non-dimensional parameters, $h / l, a / W, k_{\sigma}$, and $k_{n}$. It involves 9 different finite element meshes with $a / W=0.25,0.5$, and 0.75 , and $h / l=0.2,0.4$, and 0.8 . For each mesh, 9 analyses were performed due to 9 different mismatch factors. For the material properties, the following values were used: $E=200 \mathrm{GPa}, v=0.3$, $\sigma_{01}=300 \mathrm{MPa}, \alpha_{1}=\alpha_{2}=1$, and $n_{1}=3$. These values, in addition to the properties given in Table 3, provide complete characterization of both base and weld materials. It was assumed that the Ramberg-Osgood model can represent the tensile properties of materials adequately.

Fig. 3 shows a finite element mesh by the MSC/ PATRAN solid modeler (Version 7) $[39,40]$ for the case 3 (i.e., $a / W=0.25$ and $h / l=0.8$ ) of Table 3 . A quarter model was used to take advantage of the symmetry. Eight-noded isoparametric quadrilateral elements were used with focused elements at the crack tip. In the crack-tip region, a ring of 18-54 triangular elements was used. These triangular elements were constructed by collapsing the appropriate nodes of the eight-noded quadrilateral elements to produce the $1 / r$ strain singularity. Although this singularity is strictly valid for a fully plastic crack-tip field of non-hardening materials $\left(n_{k} \rightarrow \infty\right)$, it is practically adequate for workhardening materials as well [37]. A $2 \times 2$ Gaussian quadrature rule was used for the numerical integration. All FEAs were performed using the ABAQUS (Version 5.6) code [20]. Further details are given in Refs. [40-42].

Table 3

Matrix of finite element analysis for CCT specimens (9 runs per model)

\begin{tabular}{lllll}
\hline FEM model no. & $a / W$ & $h / l$ & $k_{\sigma}{ }^{\mathrm{a}}$ & \multicolumn{1}{l}{$k_{n}{ }^{\mathrm{b}}$} \\
\hline 1 & 0.25 & 0.2 & $0.5,1.5$, and 2 & $0.5,1.5$, and 3 \\
2 & 0.25 & 0.4 & $0.5,1.5$, and 2 & $0.5,1.5$, and 3 \\
3 & 0.25 & 0.8 & $0.5,1.5$, and 2 & $0.5,1.5$, and 3 \\
4 & 0.50 & 0.2 & $0.5,1.5$, and 2 & $0.5,1.5$, and 3 \\
5 & 0.50 & 0.4 & $0.5,1.5$, and 2 & $0.5,1.5$, and 3 \\
6 & 0.50 & 0.8 & $0.5,1.5$, and 2 & $0.5,1.5$, and 3 \\
7 & 0.75 & 0.2 & $0.5,1.5$, and 2 & $0.5,1.5$, and 3 \\
8 & 0.75 & 0.4 & $0.5,1.5$, and 2 & $0.5,1.5$, and 3 \\
9 & 0.75 & 0.8 & $0.5,1.5$, and 2 & $0.5,1.5$, and 3
\end{tabular}

${ }^{\mathrm{a}}$ The strength mismatch factor, $k_{\sigma}=\sigma_{02} / \sigma_{01} .$.

${ }^{\mathrm{b}}$ The hardening mismatch factor, $k_{n}=n_{2} / n_{1}$..

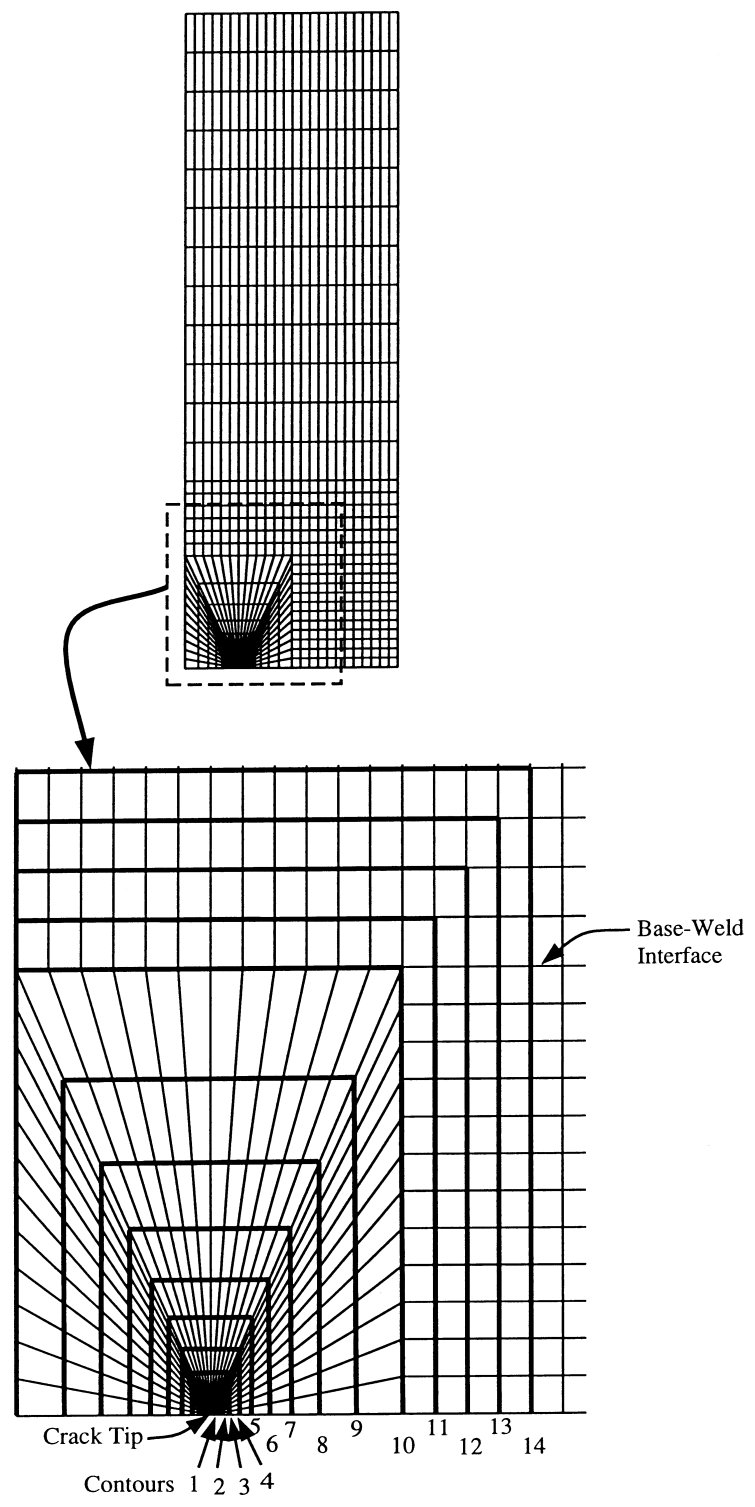

Fig. 3. A finite element mesh for $a / W=0.25$ and $h / l=0.8$ (intermediate model).

\subsection{Deterministic results and discussions}

Fig. 4 shows the convergence of $J$ vs. $\sigma^{\infty}$ results for the mismatch factors, $k_{\sigma}=0.5$ and $k_{n}=3$ using various meshes with increasing degrees of refinement. The results are practically identical. For the calculation of $J, 14$ contours were defined in the finite element meshes and are shown in Fig. 3. The values of $J$ for each of these contours are practically identical as shown by its path independence in Fig. 5 for various contour numbers. The contours $1-9$ are 


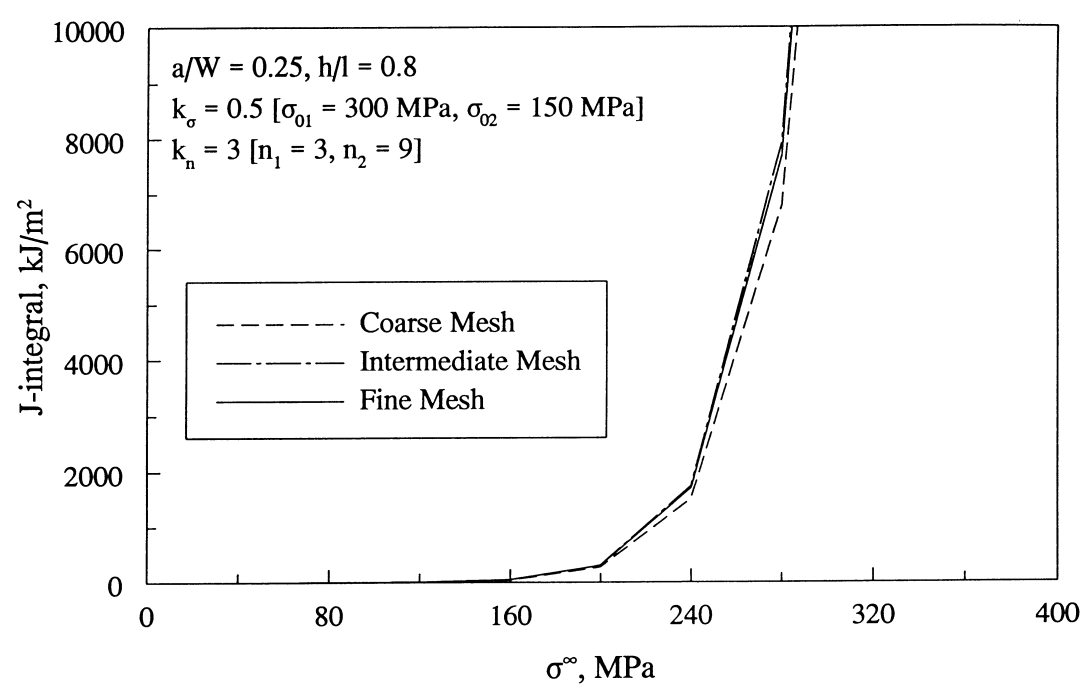

Fig. 4. $J$-integral versus far-field tensile stress for various finite element meshes.

located in the weld metal, contour 10 coincides with the base-metal interface, and contours 11-14 traverse the base-metal interface. The variations with respect to the average value of $J$ from all contours were less than $3 \%$. The results in Fig. 4 correspond to $J$ for the third contour. In summary, the intermediate mesh (Fig. 3) is quite satisfactory with the largest difference between its results and those from the fine mesh is about $3.5 \%$. Hence, finite element meshes similar to Fig. 3 were used for the rest of the analyses. For the sake of brevity, only the results of the extreme cases of Table 3 will be discussed in this paper.

Fig. 6(a)-(d) show $J$ vs. $\sigma^{\infty}$ plots for the case 1 mesh generated for a small crack $(a / W=0.25)$ and a small weld width $(h / l=0.2)$ and for four extreme cases of strength and hardening mismatch factors. For each case, the $J$ values were calculated from three separate analyses based on tensile properties of all-base, allweld, and base and weld materials. The analyses were performed until $\sigma^{\infty}$ reaches $\sigma_{0}^{\infty}$, where $\sigma_{0}^{\infty}$ is the farfield tensile stress (based on the higher reference stress)

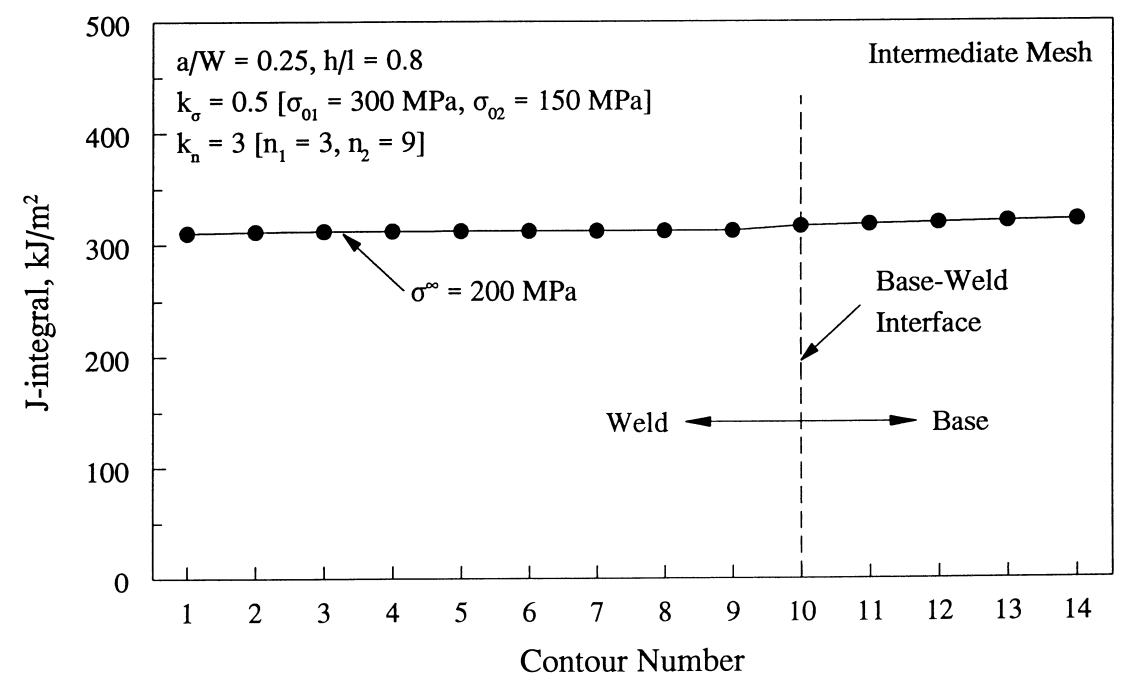

Fig. 5. Path independence of $J$ for a weld crack in a CCT specimen. 

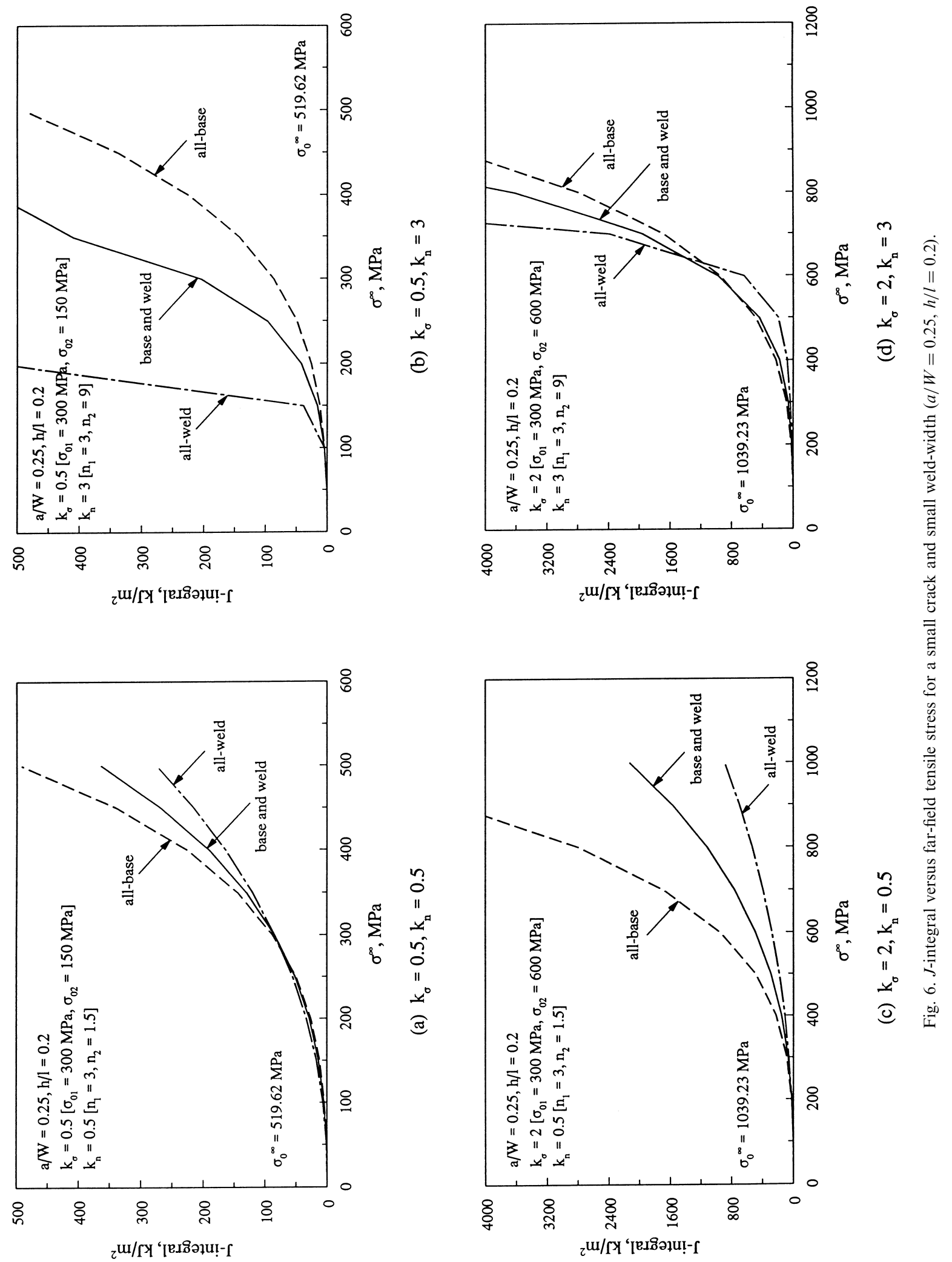

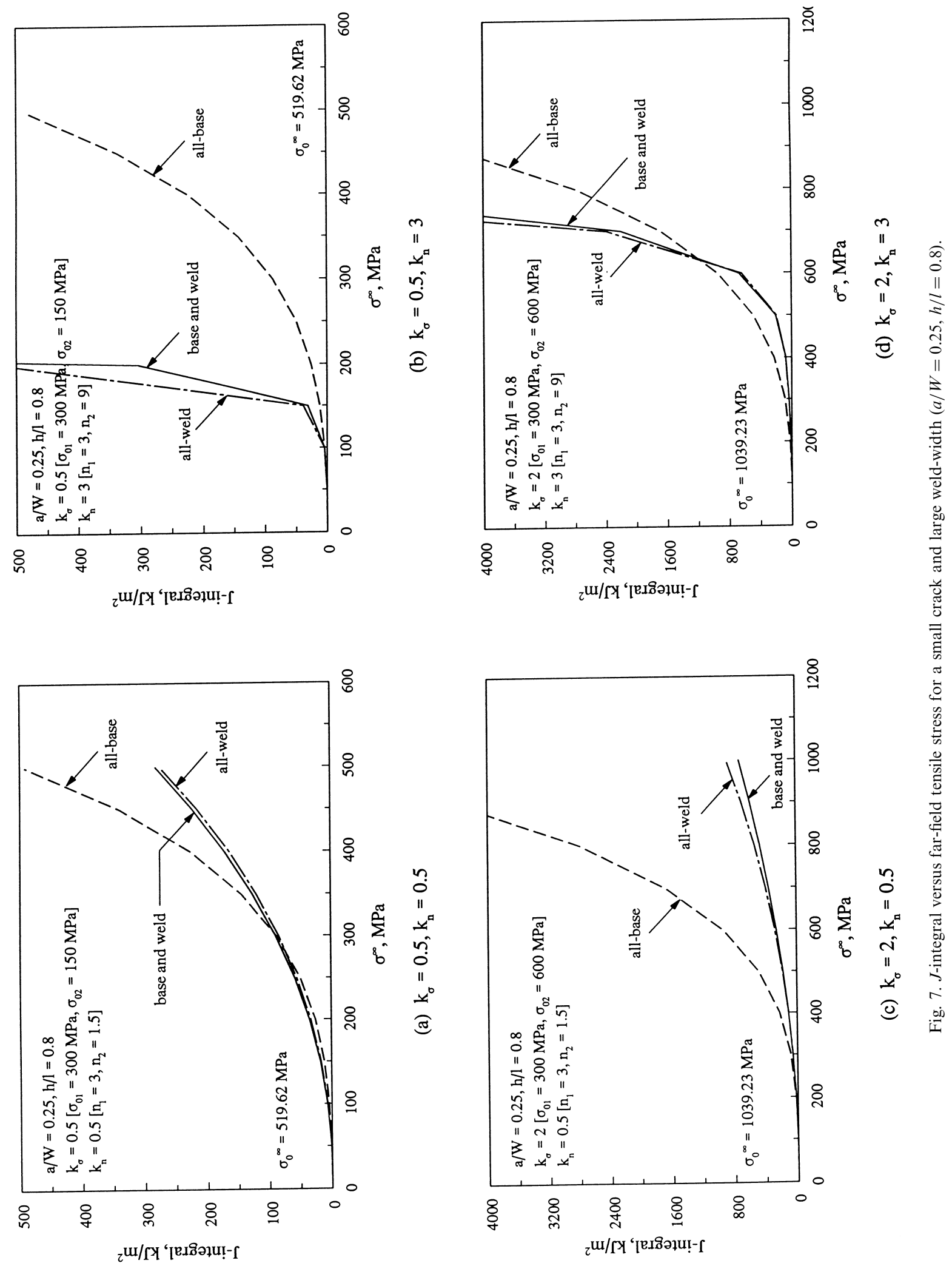

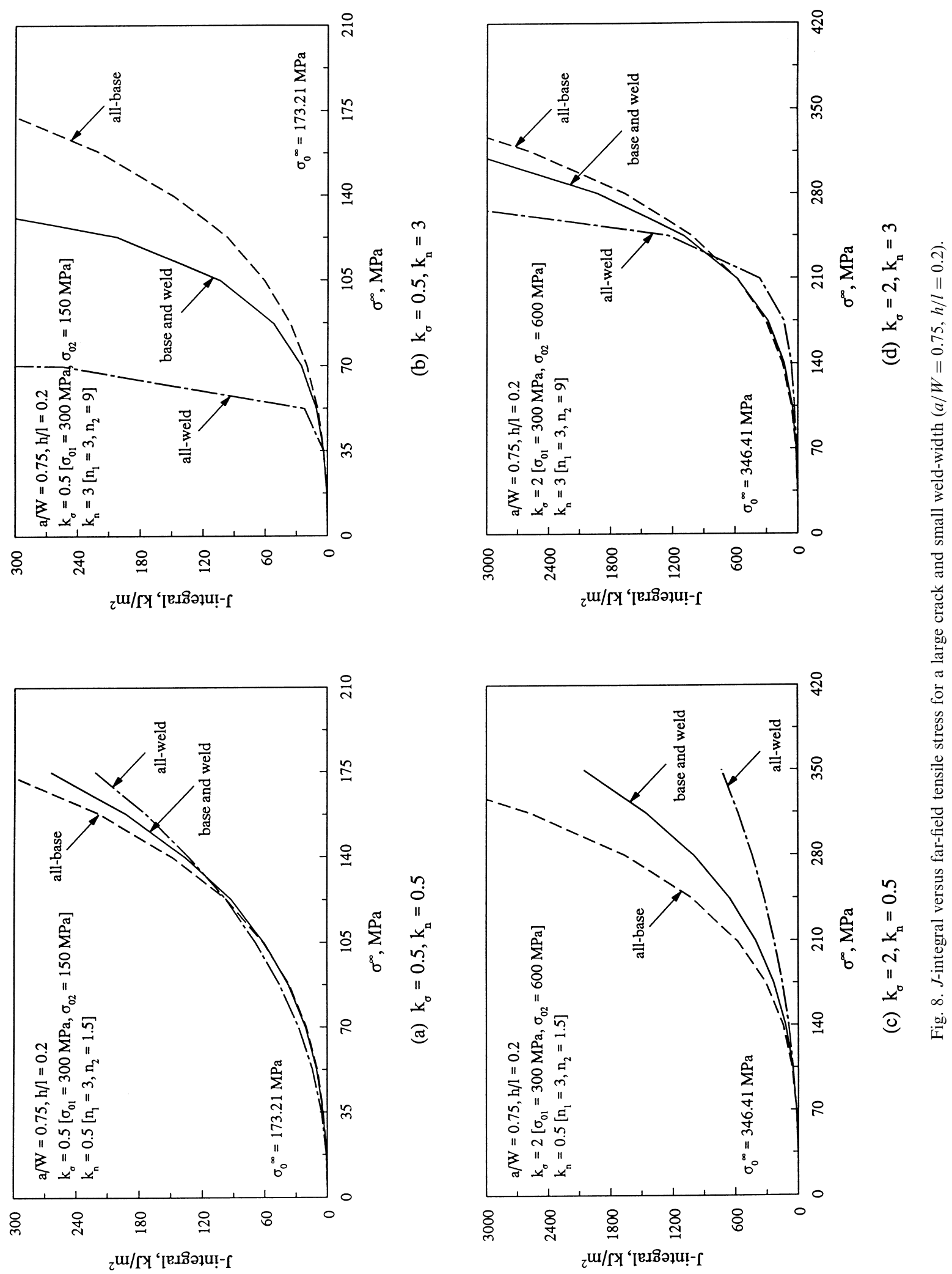

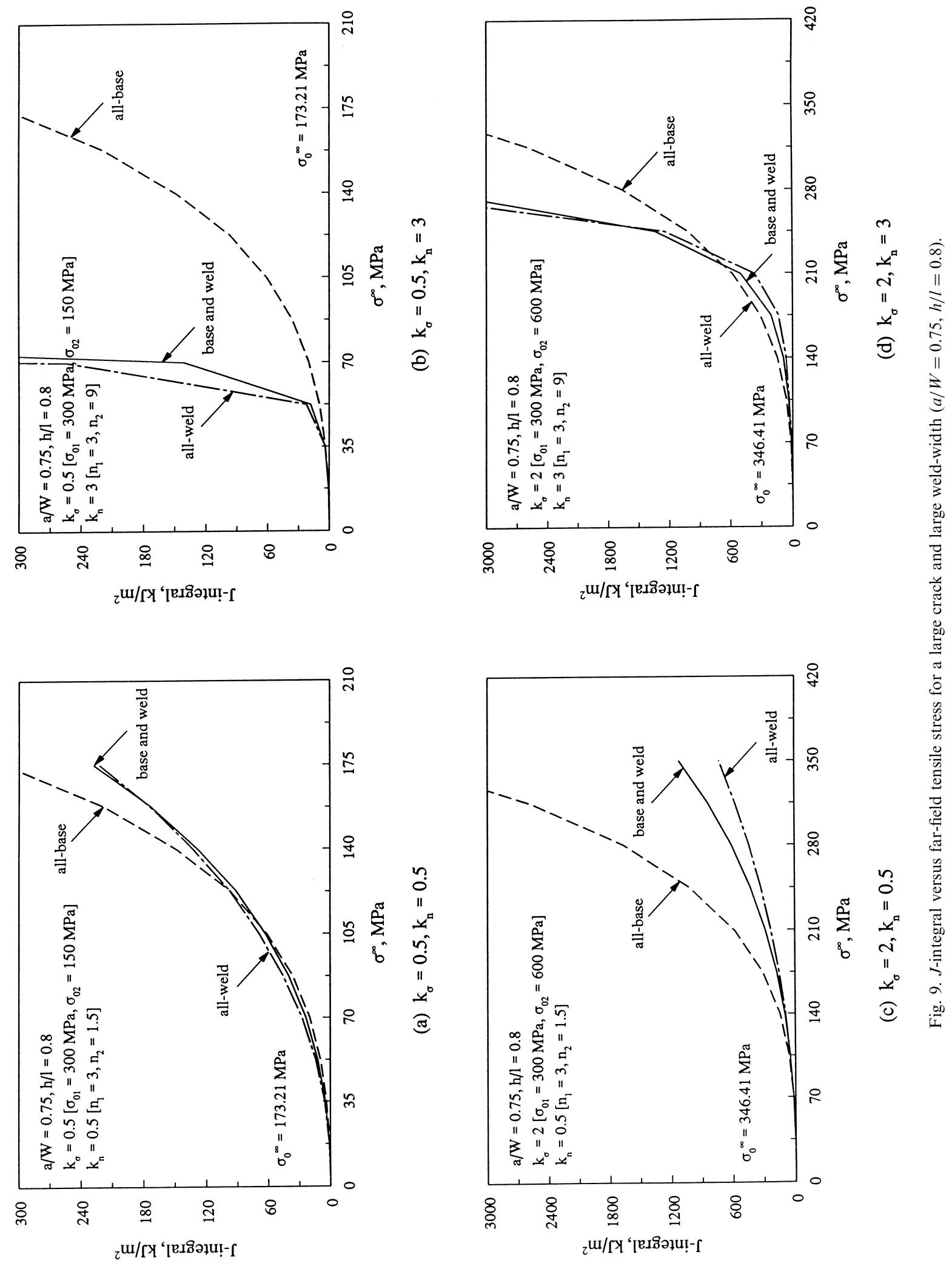
that corresponds to the reference load, $P_{0}$, defined by Kumar et al. [38]. ${ }^{1}$ Fig. 6(a) represents the behavior of a CCT weld specimen, which is undermatched with respect to strength, but overmatched with respect to material work hardening. ${ }^{2}$ For small load intensities, the $J$ values from all three analyses are close to each other, with $J$ calculated from the all-weld analysis being slightly higher than that calculated from all-base analysis. However, for large load intensities, these curves cross each other and the $J$-values from the allbase analysis become much higher than those from the all-weld analysis. This mixed behavior is due to the mixed mismatched condition with respect to strength and material work hardening. Also, $J$ for a welded CCT specimen lies between the results of all-base and all-weld analyses, and hence, it cannot be predicted by all-base or all-weld tensile properties alone. This is more clearly observed in Fig. 6(b), which shows similar plots of $J$ vs. $\sigma^{\infty}$ for a truly undermatched case (i.e., undermatched with respect to both strength and hardening). In this case, the $J$ values from the all-weld analysis are much higher than those from the all-base analysis due to much weaker weld material. A completely opposite behavior is exhibited in Fig. 6(c), which represents a case with a truly overmatched condition. The $J$ values from the all-base analysis are now much higher than those from the all-weld analysis due to a much weaker base material. Finally, Fig. 6(d) shows the results of the remaining case with the other mixed mismatched condition. In this case, the CCT weld specimen is overmatched with respect to strength, but undermatched with respect to material work hardening. The trends in Fig. 6(d) show an opposite behavior to those in Fig. 6(a) as expected. In all cases, the results indicate that the tensile properties of both base and weld materials should be accounted for when calculating $J$ of a welded structure.

Fig. 7(a)-7(d) show $J$ vs. $\sigma^{\infty}$ plots for the case 3 mesh generated for a small crack $(a / W=0.25)$ and a large weld width $(h / l=0.8)$. As before, the results of four extreme cases are presented. The trends in the results of all-base and all-weld analyses are identical to the ones in Fig. 6(a)-(d). However, in Fig. 7(a)-(d), the $J$ values for the weld specimen are extremely close to the $J$ values from all-weld analyses. This is because of the large width of the weld chosen, which allowed

\footnotetext{
${ }^{1}$ According to Kumar et al. [38], $P_{0}=4 B l \sigma_{0} / \sqrt{ } 3$, where $B$ is specimen thickness and $\sigma_{0}$ is reference stress.

${ }^{2}$ In this paper, a weld joint is overmatched (undermatched) with respect to strength when the strength of weld metal is higher (lower) than that of base metal. Also, a weld joint is overmatched (undermatched) with respect to material hardening when the hardening exponent of weld metal is lower (higher) than that of base metal.
}

little effect from the base metal properties. Hence, the fracture behavior for these cases can be adequately described by the weld properties alone.

Fig. 8(a)-(d) show similar results of $J$ for the case 7 mesh generated for a large crack $(a / W=0.75)$ and a small weld width $(h / l=0.2)$. Due to the large crack sizes, the $J$ values for a given applied load are much higher than those for small cracks, in general. Otherwise, the trends are identical to those in Fig. 6(a)-(d).

Finally, Fig. 9(a)-9(d) show $J$ vs. $\sigma^{\infty}$ plots for the case 9 mesh generated for a large crack $(a / W=0.75)$ and a large weld width $(h / l=0.8)$. Once again, the $J$ values for a given load are much higher when compared with those for small cracks as shown in Fig. 7(a)-(d). The qualitative behavior of the $J$ vs. $\sigma^{\infty}$ plots for small and large cracks is similar.

\section{Probabilistic fracture analysis}

\subsection{Analytical approximation of $J$}

Under elastic-plastic condition and the deformation theory of plasticity when the stress-strain curve is modeled by Eq. (4), the total crack driving force, $J$, for a welded CCT specimen can be obtained by adding the elastic component, $J_{\mathrm{e}}$, and the plastic component, $J_{\text {p, i.e., }}$

$J=J_{\mathrm{e}}+J_{\mathrm{p}}$.

$J_{\mathrm{e}}$ is identical to that of a CCT specimen with the crack in either base or weld metal, because their elastic properties are similar. However, the calculation of $J_{\mathrm{p}}$ is more difficult, but it can be approximated based on the FEM solutions. These solutions are briefly described below.

\subsubsection{Elastic solution}

Under plane-strain condition, the elastic component, $J_{\mathrm{e}}$, is [38]

$J_{\mathrm{e}}=\frac{K_{\mathrm{I}}^{2}}{E}\left(1-v^{2}\right)$

where, $K_{\mathrm{I}}$ is the mode-I stress-intensity factor, given by [37,38]

$$
\begin{aligned}
K_{\mathrm{I}} & =2 \sigma^{\infty} \sqrt{W} \sqrt{\frac{\pi a}{4 W} \sec \frac{\pi a}{2 W}}\left[1-0.025\left(\frac{a}{W}\right)^{2}\right. \\
& \left.+0.06\left(\frac{a}{W}\right)^{4}\right]
\end{aligned}
$$




\subsubsection{Plastic solution}

From the observation of FEM results (see Figs. 69), the plastic component, $J_{\mathrm{p}}$, can be approximated by superposing contributions from all-base $\left(J_{\mathrm{p}}^{\mathrm{B}}\right)$ and allweld $\left(J_{\mathrm{p}}^{\mathrm{W}}\right)$ solutions. For example, a simple way of approximating $J_{\mathrm{p}}$ for CCT weld specimen is

$$
\begin{aligned}
J_{\mathrm{p}} & =c\left(\frac{a}{W}, \frac{h}{l}, k_{\sigma}, k_{n}\right) J_{\mathrm{p}}^{\mathrm{B}} \\
& +\left[1-c\left(\frac{a}{W}, \frac{h}{l}, k_{\sigma}, k_{n}\right)\right] J_{\mathrm{p}}^{\mathrm{W}}
\end{aligned}
$$

where

$$
J_{\mathrm{p}}^{\mathrm{B}}=\alpha_{1} \frac{\sigma_{01}^{2}}{E} \frac{l a}{W} h_{1}^{\mathrm{B}}\left(\frac{a}{W}, n_{1}\right)\left(\frac{2 B W \sigma^{\infty}}{P_{0}^{\mathrm{B}}}\right)^{n_{1}+1},
$$

$$
J_{\mathrm{p}}^{\mathrm{W}}=\alpha_{2} \frac{\sigma_{02}^{2}}{E} \frac{l a}{W} h_{1}^{W}\left(\frac{a}{W}, n_{2}\right)\left(\frac{2 B W \sigma^{\infty}}{P_{0}^{\mathrm{W}}}\right)^{n_{2}+1},
$$

$h_{1}^{\mathrm{B}}$ and $h_{1}^{\mathrm{W}}$ are plastic influence functions [38], $P_{0}^{\mathrm{B}}$ and $P_{0}^{\mathrm{W}}$ are reference loads with the superscripts ' $\mathrm{B}$ ' and ' $\mathrm{W}$ ' signifying base- and weld-metal analysis or proper-

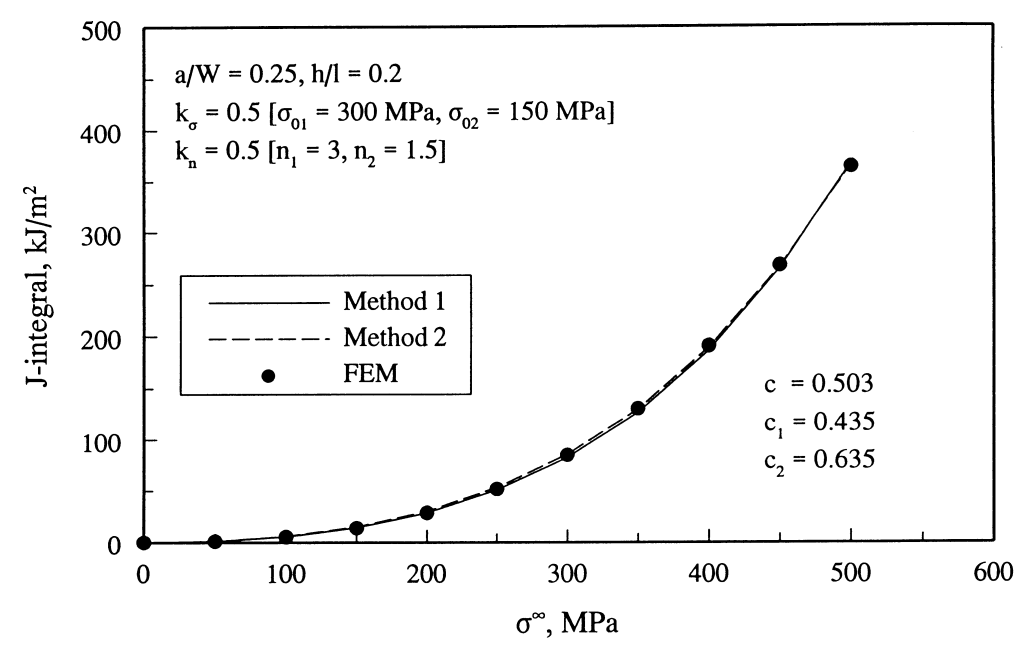

(a) $a / W=0.25, h / l=0.2, k_{\sigma}=0.5$, and $k_{n}=0.5$

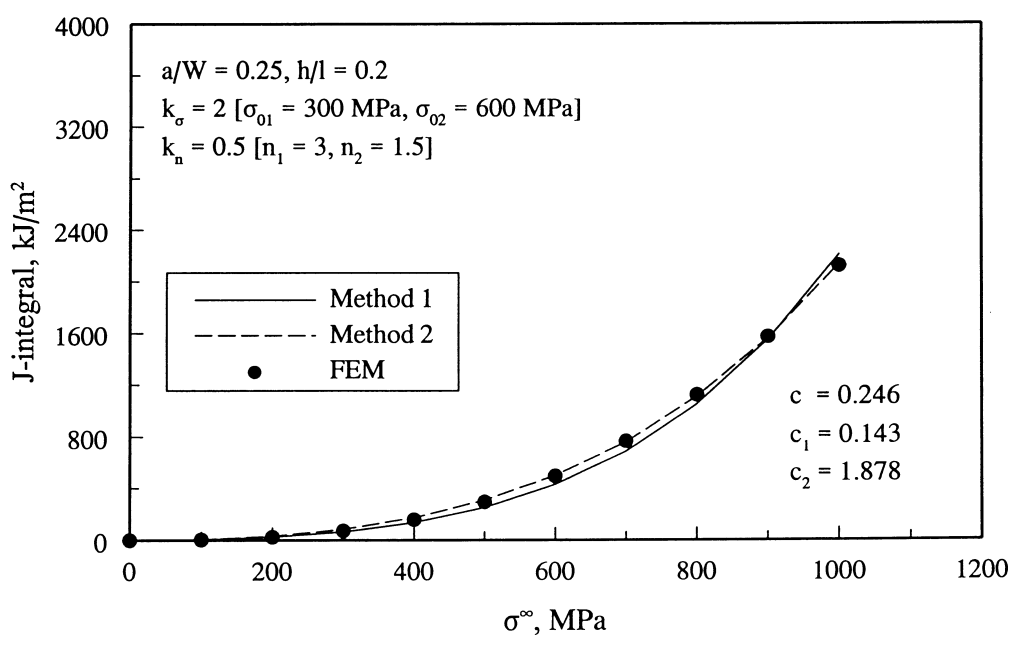

(b) $a / W=0.25, h / l=0.2, k_{\sigma}=2$, and $k_{n}=0.5$

Fig. 10. Comparisons of analytic approximations of $J$ with FEM. 
ties, respectively, and $c$ is a linear participation factor due to all-base $J$-integral analysis. In general, $c$ depends on geometric parameters, $a / W$ and $h / l$, and material mismatch factors, $k_{\sigma}$ and $k_{n}$. It can be empirically determined by matching Eq. (7) with the generally more accurate FEM results. The calculation of $J$ by Eqs. (7) and (10) will be denoted as Method 1 in this paper.

A slightly more generalized form of Eq. (10) is

$J_{\mathrm{p}}=c_{1}\left(\frac{a}{W}, \frac{h}{l}, k_{\sigma}, k_{n}\right) J_{\mathrm{p}}^{\mathrm{B}}+c_{2}\left(\frac{a}{W}, \frac{h}{l}, k_{\sigma}, k_{n}\right) J_{\mathrm{p}}^{\mathrm{W}}$

which involves two independent parameters, $c_{1}$ and $c_{2}$ that perhaps would fit the FEM results more accurately. The calculation of $J$ by Eqs. (7) and (13) will be denoted as Method 2 in this paper. Alternative equations representing more complicated and a possibly nonlinear interaction between $J_{\mathrm{p}}^{\mathrm{B}}$ and $J_{\mathrm{p}}^{\mathrm{W}}$ can be developed, but they were not considered in this study. Only Eqs. (10) and (13) were used in this paper. The parameters, $c, c_{1}$, and $c_{2}$ were estimated by standard least-squares regression of finite element results.

To evaluate the adequacy of approximations in Eqs. (10) and (13), Fig. 10 shows the comparisons of $J$ vs. $\sigma^{\infty}$ plots from these equations with the elastic-plastic FEM solutions. The results in Fig. 10 were generated for $a / W=0.2, h / l=0.2$ and two cases of material mismatch factors: $k_{\sigma}=0.5, k_{n}=0.5$ and $k_{\sigma}=2, k_{n}=$ 0.5. The agreement between the analytical approximations by both methods and FEM is excellent. Due to the simplicity, Method 1 (Eq. (10)) was used for subsequent probabilistic calculations. Although these analytical forms of $J$ are not needed for deterministic calculations, they are quite useful for probabilistic analysis [42-44]. It is described in the following sections.

\subsection{Random parameters and fracture response}

Consider a cracked structure with uncertain mechanical and geometric characteristics that is subject to random loads. Denote by $\mathbf{X}$ an $N$-dimensional random vector with components characterizing all uncertainties in the system and load parameters. For example, when a CCT weld specimen is considered, the possible random components are: geometric parameters, $a, W$, and $h$, material tensile parameters, $E, v, \alpha_{1}, \alpha_{2}, n_{1}$, and $n_{2}$, fracture toughness parameters, $J_{\text {Ic }}, C$, and $m,(C$ and $m$ are $J-R$ curve parameters) and applied far-field stress, $\sigma^{\infty}$. All or some of these variables can be modeled as random variables. Hence, any relevant fracture response, such as the $J$-integral, $J(\mathbf{X})$, should be evaluated by the probability
$F_{J}\left(j_{0}\right) \stackrel{\text { def }}{=} \operatorname{Pr}\left[J(\mathbf{X})<j_{0}\right]=\int_{J(\mathbf{X})_{<j 0}} f_{\mathbf{X}}(\mathbf{x}) \mathrm{d} \mathbf{x}$

or the probability density function (PDF), $f_{J}\left(j_{0}\right)=\mathrm{d} F_{J}\left(j_{0}\right) / \mathrm{d} j_{0}$, where $F_{J}\left(j_{0}\right)$ is the cumulative distribution function of $J$ and $f_{\mathbf{X}}(\mathbf{x})$ is the known joint PDF of input random vector $\mathbf{X}$.

The fracture parameter $J$ can also be applied to calculate structural integrity and hence, failure probability, $P_{\mathrm{F}}$, of cracked structures. This failure probability depends on the failure criteria, some of which are defined by Eqs. (2) and (3). For example, if the initiation of crack growth in the CCT specimen constitutes a failure condition, $P_{\mathrm{F}}$ can be written as

$P_{\mathrm{F}}=\operatorname{Pr}[g(\mathbf{X})<0]=\int_{g(\mathbf{x})<0} f_{\mathbf{X}}(\mathbf{x}) \mathrm{d} \mathbf{x}$

where,

$g(\mathbf{X})=J_{\text {Ic }}-J(\mathbf{X})$.

Note, if $j_{0}$ represents the material fracture toughness at crack initiation $\left(J_{\mathrm{Ic}}\right), P_{\mathrm{F}}$ is simply the complement of $F_{J}\left(j_{0}\right)$, i.e., $P_{\mathrm{F}}=1-F_{J}\left(j_{0}\right)$. The failure probability, $P_{\mathrm{F}}$ in Eq. (15) corresponds to the probability of initiation of crack growth, which provides a conservative estimate of structural performance. A more realistic evaluation of structural reliability requires calculating the probability of fracture instability following crack initiation. See Ref. [42] for further details.

\subsection{Structural reliability analysis}

The generic expression for the failure probability in Eq. (15) involves multi-dimensional probability integration for its evaluation. In this study, standard reliability methods, such as FORM/SORM [45-59], and MCS [60] were used to compute these probabilities. They are used here to calculate the probability of failure, $P_{\mathrm{F}}$ in Eq. (15) assuming a generic $N$-dimensional random vector $\mathbf{X}$ and the performance function $g(\mathbf{x})$ defined by Eq. (16). A brief description of FORM/ SORM and MCS methods is given below.

\subsubsection{FORM/SORM}

The FORM/SORM are based on linear (first-order) and quadratic (second-order) approximations of the limit state surface $g(\mathbf{x})=0$ tangent to the closest point of the surface to the origin of the space. The determination of this point involves nonlinear constrained optimization and is usually performed in the standard Gaussian image of the original space. The FORM/ SORM algorithms involve several steps. First, the space $\mathbf{x}$ of uncertain parameters $\mathbf{X}$ is transformed into a new $\mathrm{N}$-dimensional space $\mathbf{u}$ consisting of independent standard Gaussian variables $\mathbf{U}$. The original limit state 
$g(\mathbf{x})=0$ then becomes mapped into the new limit state $g_{U}(\mathbf{u})=0$ in the $\mathbf{u}$ space. Second, the point on the limit state $g_{U}(\mathbf{u})=0$ having the shortest distance to the origin of the $\mathbf{u}$ space is determined by using an appropriate nonlinear optimization algorithm. This point is referred to as the design point or beta point, and has a distance $\beta_{\mathrm{HL}}$ (known as reliability index) to the origin of the $\mathbf{u}$ space. Third, the limit state $g_{U}(\mathbf{u})=0$ is approximated by a surface tangent to it at the design point. Let such limit states be $g_{\mathrm{L}}(\mathbf{u})=0$ and $g_{\mathrm{Q}}(\mathbf{u})=0$, which correspond to approximating surfaces as hyperplane (linear or first-order) and hyperparaboloid (quadratic or second-order), respectively. The probability of failure $P_{\mathrm{F}}$ (Eq. (15)) is thus approximated by $\operatorname{Pr}\left[g_{\mathrm{L}}(\mathbf{U})<0\right]$ in FORM and $\operatorname{Pr}\left[g_{\mathrm{Q}}(\mathbf{U})<0\right]$ in SORM. These first-order and second-order estimates $P_{\mathrm{F}, 1}$ and $P_{\mathrm{F}, 2}$ are given by [45-59]

$$
P_{\mathrm{F}, 1}=\Phi\left(-\beta_{\mathrm{HL}}\right)
$$

$$
P_{\mathrm{F}, 2} \cong \Phi\left(-\beta_{\mathrm{HL}}\right) \prod_{i=1}^{N-1}\left(1-\kappa_{i} \frac{\phi\left(-\beta_{\mathrm{HL}}\right)}{\Phi\left(-\beta_{\mathrm{HL}}\right)}\right)^{-1 / 2}
$$

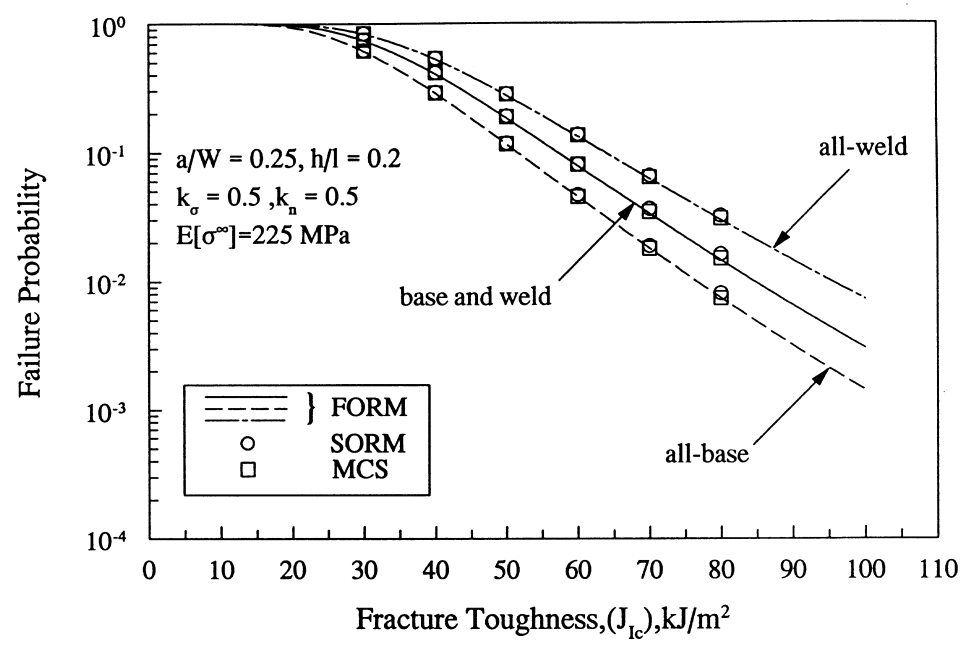

(a) Failure probability

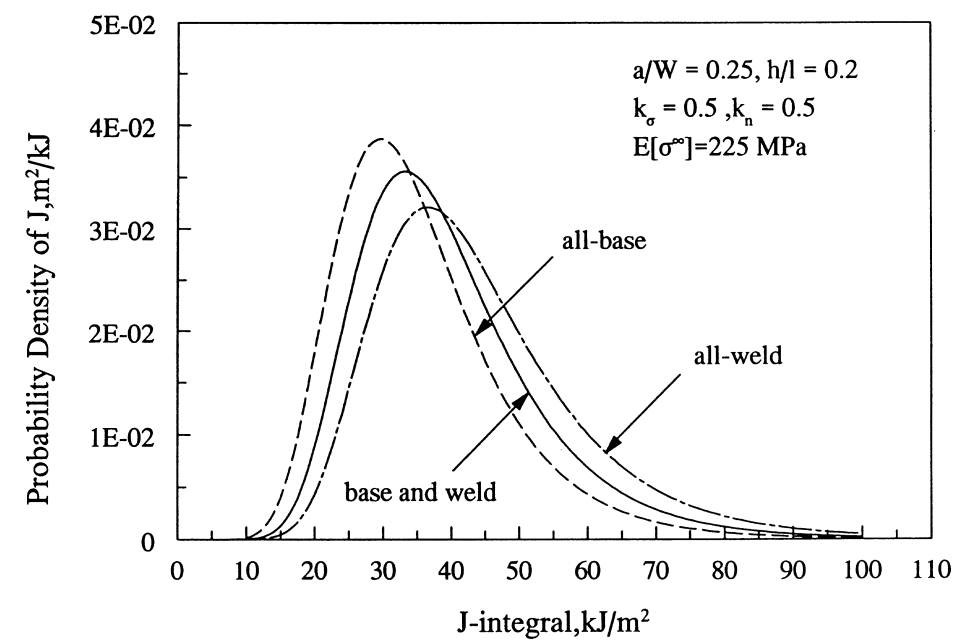

(b) PDF of J-integral

Fig. 11. Probabilistic results for $a / W=0.25, h / l=0.2, k_{\sigma}=0.5$, and $k_{n}=0.5\left(E\left[\sigma^{\infty}\right]=225 \mathrm{MPa}\right)$. 
where

$\phi(u)=\frac{1}{\sqrt{2 \pi}} \exp \left(-\frac{1}{2} u^{2}\right)$

$\Phi(u)=\frac{1}{\sqrt{2 \pi}} \int_{-\infty}^{u} \exp \left(-\frac{1}{2} \xi^{2}\right) \mathrm{d} \xi$

are the probability density and cumulative distribution functions, respectively, of a standard Gaussian random variable, and $\kappa_{i}$ 's are the principal curvatures of the limit state surface at the design point. Further details of FORM/SORM equations are available in Refs. [4559].

FORM/SORM are standard computational methods of structural reliability theory. In this study, a modified HL-RF algorithm, described in Appendix A, was used to solve the associated optimization problem. The firstand second-order sensitivities were calculated numerically by the finite difference method.

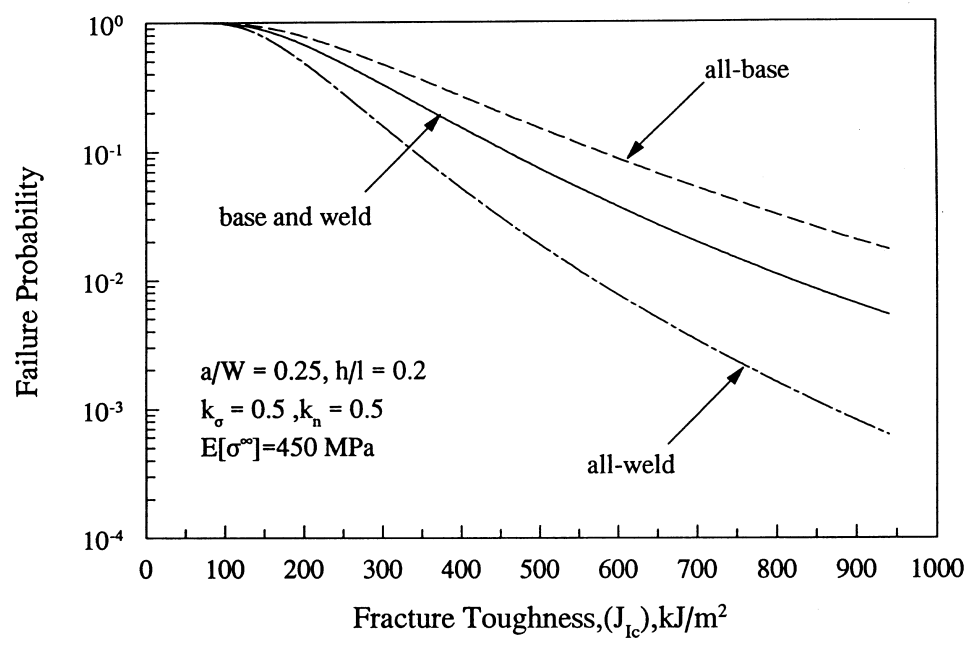

(a) Failure probability

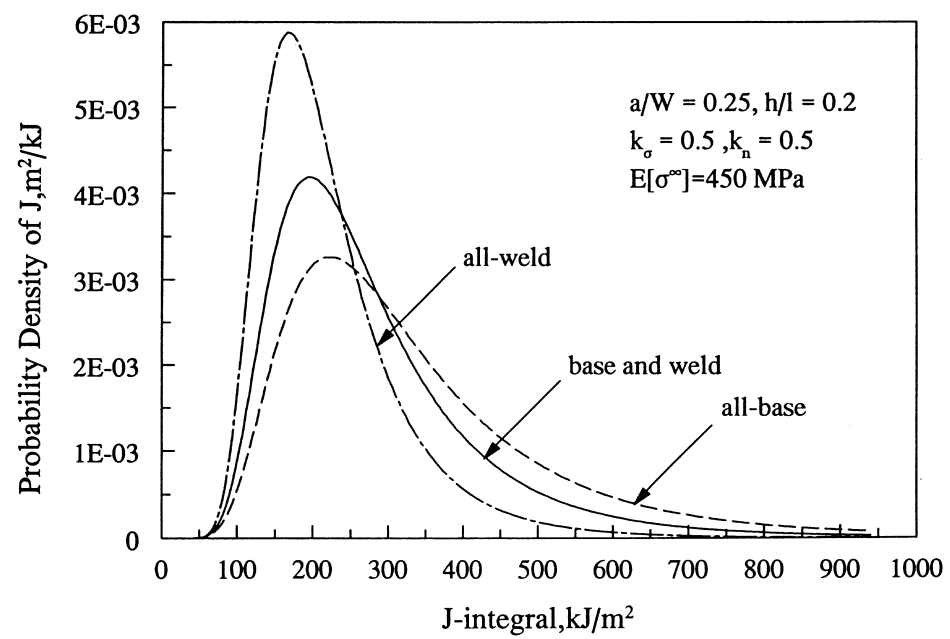

(b) PDF of J-integral

Fig. 12. Probabilistic results for $a / W=0.25, h / l=0.2, k_{\sigma}=0.5$, and $k_{n}=0.5\left(E\left[\sigma^{\infty}\right]=450 \mathrm{MPa}\right)$. 


\subsection{2. $M C S$}

Consider a generic $N$-dimensional random vector $\mathbf{X}$ which characterizes uncertainty in all load and system parameters with the known joint distribution function, $F_{\mathbf{X}}(\mathbf{x})$. Suppose that $\mathbf{x}^{(1)}, \mathbf{x}^{(2)}, \ldots, \mathbf{x}^{(L)}$ are $L$ realizations of input random vector, $\mathbf{X}$, which can be generated independently. Rubinstein [60] provides a simple method to generate $\mathbf{X}$ from its known probability distribution. Let $g^{(1)}, g^{(2)}, \ldots, g^{(L)}$ be the output samples of $g(\mathbf{X})$ corresponding to the input $\mathbf{x}^{(1)}, \mathbf{x}^{(2)}, \ldots, \mathbf{x}^{(L)}$ that can be obtained by conducting repeated deterministic evaluation of the performance function in Eq. (16). Define $L_{\mathrm{f}}$ as the number of trials, which are associated with negative values of the performance function. Then, the estimate $P_{\mathrm{F}, \mathrm{MCS}}$ by simulation becomes

$$
P_{\mathrm{F}, \mathrm{MCS}}=\frac{L_{\mathrm{f}}}{L}
$$

which approaches the exact failure probability $P_{\mathrm{F}}$ when $L$ approaches infinity. When $L$ is finite, a statistical estimate on the probability estimator may be needed. In general, the required sample size must be at least $10 / \operatorname{Min}\left(P_{\mathrm{F}}, 1-P_{\mathrm{F}}\right)$ for a $30 \%$ coefficient of variation of the estimator [60].

\subsection{Probabilistic results and discussions}

For the probabilistic analysis, it was assumed that both the load and material properties were random. Table 4 shows the means, coefficients of variation

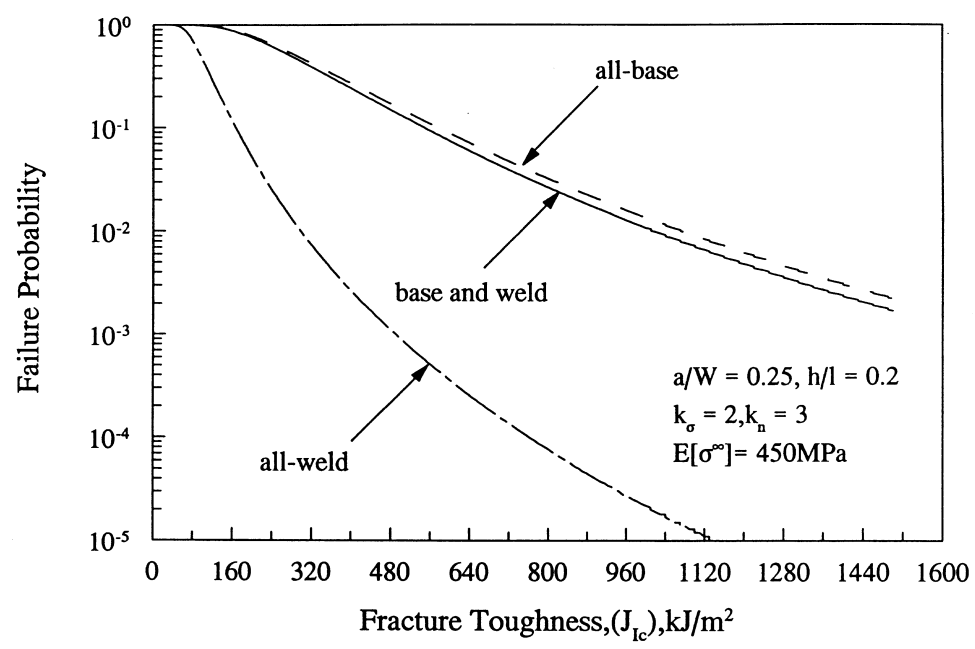

(a) Failure probability

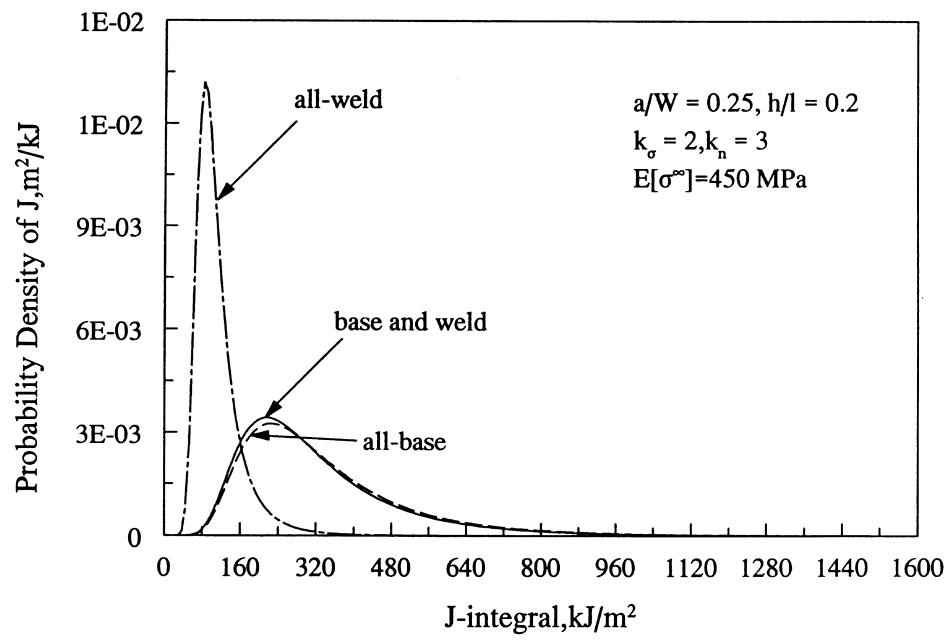

Fig. 13. Probabilistic results for $a / W=0.25, h / l=0.2, k_{\sigma}=2$, and $k_{n}=3\left(E\left[\sigma^{\infty}\right]=450 \mathrm{MPa}\right)$. 
Table 4

Statistical properties of random input for CCT weld specimen

\begin{tabular}{llll}
\hline Random variable & Mean & COV & Probability distribution \\
\hline$E$ & $200 \mathrm{GPa}$ & 0.05 & Gaussian \\
$\alpha_{1}$ & 1 & 0.439 & Lognormal \\
$n_{1}{ }^{\mathrm{a}}$ & 3 & 0.146 & Lognormal \\
$\alpha_{2}{ }^{\mathrm{a}}$ & 1 & 0.439 & Lognormal \\
$n_{2}{ }^{\infty}$ & $3 k_{n}{ }^{\mathrm{b}}$ & 0.146 & Lognormal \\
$\sigma^{\infty}$ & Variable $^{\mathrm{c}}$ & 0.1 & Gaussian \\
\hline
\end{tabular}

${ }^{\text {a }}$ Perfectly correlated with corresponding base-metal properties.

${ }^{\mathrm{b}} k_{n}$ is deterministic and varies from 0.5 to 3 .

${ }^{\mathrm{c}}$ Arbitrarily varied.
(COV), and probability distributions of load and tensile parameters. The mean values were chosen arbitrarily and these same values were used for the deterministic FEA discussed earlier. However, the $\mathrm{COV}$ and probability distributions of these variables came from recently performed statistical characterization of Type 304 stainless steel at $288^{\circ} \mathrm{C}(550 \mathrm{~F})$ [61]. These random variables were assumed to be statistically independent. The weld-metal tensile parameters were defined by specifying the values of $k_{\sigma}$ and $k_{n}$. Hence, the weld-metal parameters are also random, but they are perfectly correlated with base-metal parameters. The variability in load was defined arbitrarily.

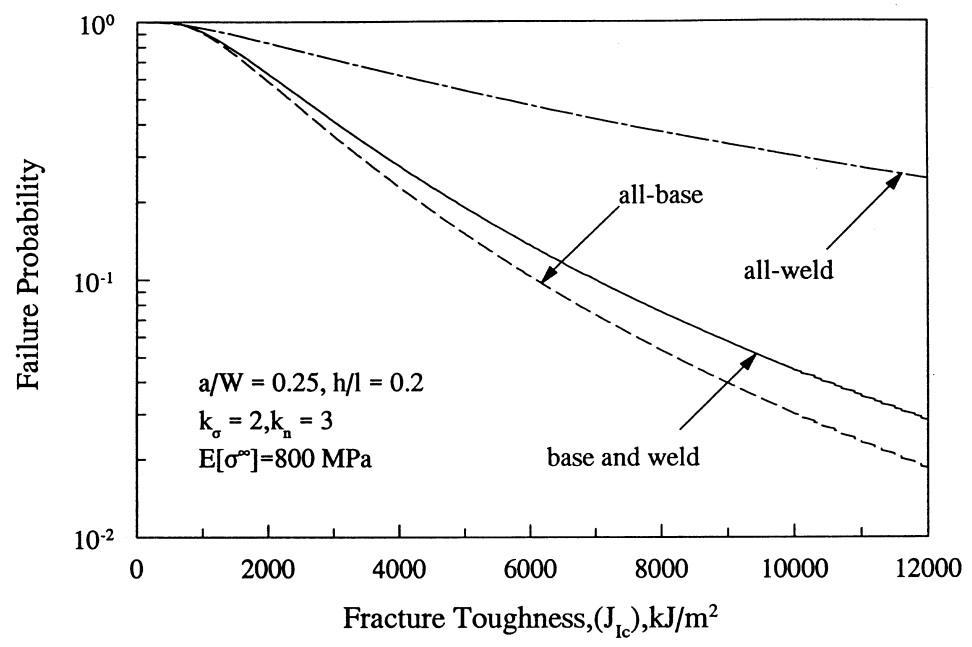

(a) Failure probability

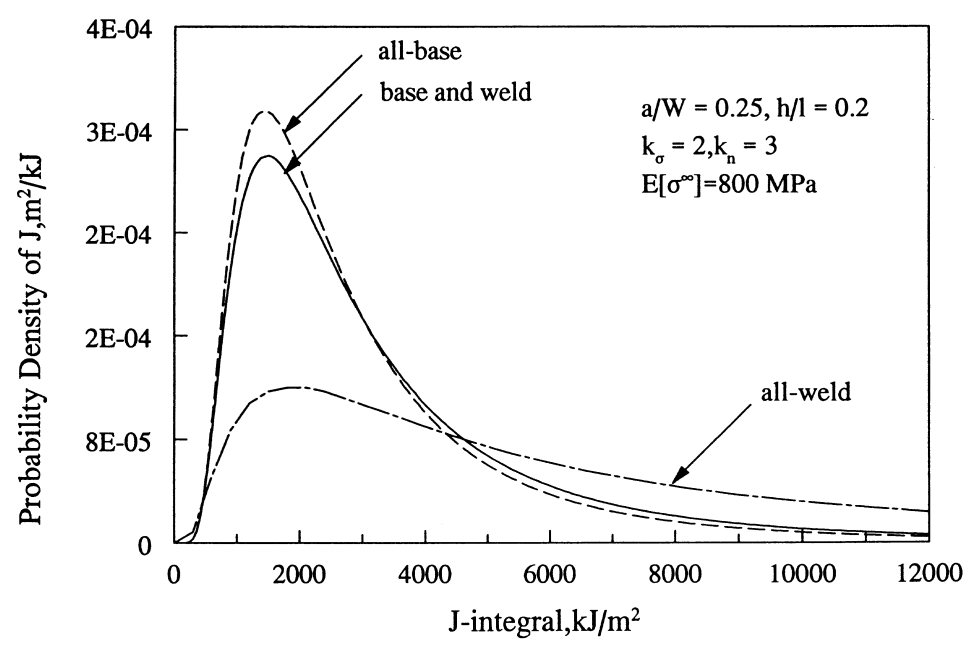

(b) PDF of J-integral

Fig. 14. Probabilistic results for $a / W=0.25, h / l=0.2, k_{\sigma}=2$, and $k_{n}=3\left(E\left[\sigma^{\infty}\right]=800 \mathrm{MPa}\right)$. 
The deterministic parameters are: $\sigma_{01}=300 \mathrm{MPa}$, and $v=0.3$.

Using FORM/SORM, the failure probability and probabilistic characteristics of $J$ were calculated for the CCT weld specimen. For the sake of brevity, the results for a small crack $(a / W=0.25)$ and small weld width $(h / l=0.2)$ and for four extreme cases of strength and hardening mismatch factors, i.e., (a) $k_{\sigma}=0.5, k_{n}=0.5$; (b) $k_{\sigma}=0.5, k_{n}=3$; (c) $k_{\sigma}=2$, $k_{n}=0.5$; and (d) $k_{\sigma}=2, k_{n}=3$, are presented here.

Consider the case of $k_{\sigma}=0.5, k_{n}=0.5$, which represents a weld specimen undermatched with respect to strength, but overmatched with respect to material work hardening. Fig. 11(a) shows the failure probability, $P_{\mathrm{F}}$, for this weld joint as a function of fracture initiation toughness, $J_{\mathrm{Ic}}$, when the mean far-field tensile stress is $225 \mathrm{MPa}$ (small). Three plots generated from probabilistic analyses based on tensile properties of all-base, all-weld, and base and weld materials are shown. A number of observations can be made. First, the failure probabilities calculated by FORM compare extremely well with the generally more accurate results of SORM and MCS. Hence, the rest of the probabilistic calculations can be based on FORM. Second, the probability of failure decreases with $J_{\text {Ic }}$ regardless of what tensile properties are used and is expected. Third,

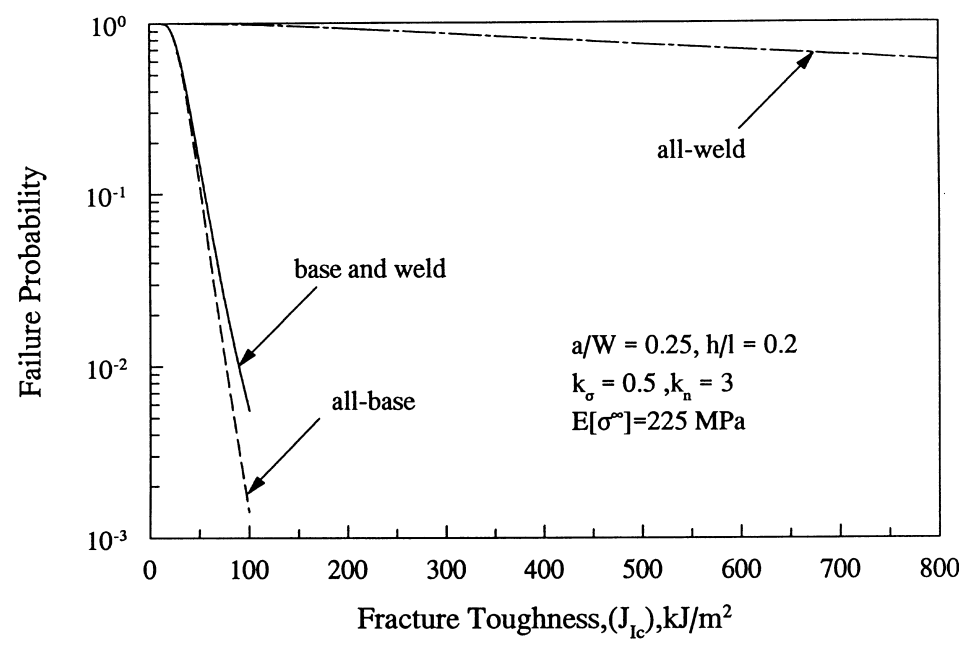

(a) Failure probability

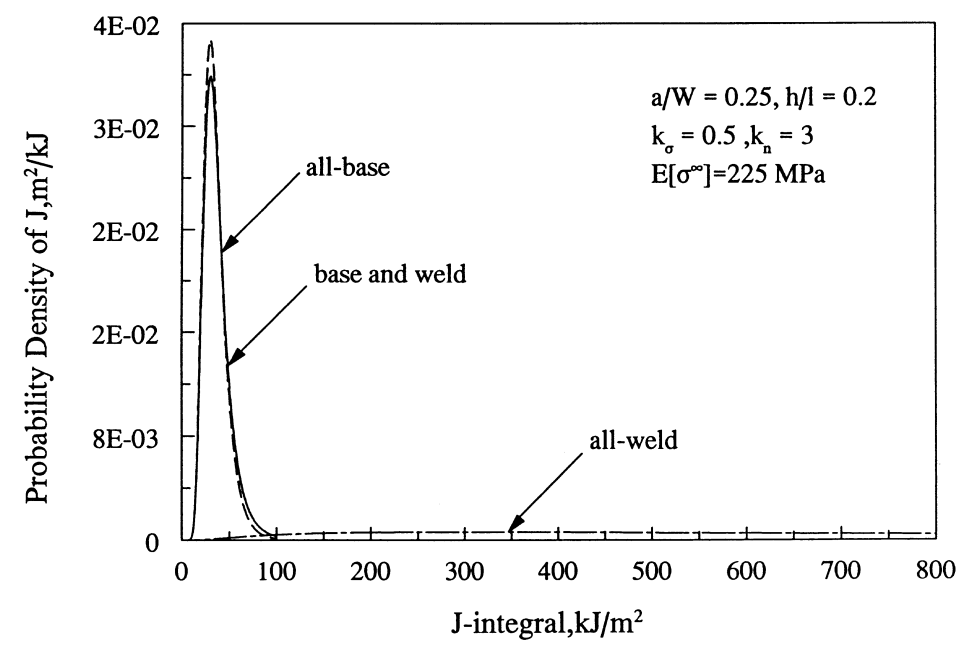

(b) PDF of J-integral

Fig. 15. Probabilistic results for $a / W=0.25, h / l=0.2, k_{\sigma}=0.5$, and $k_{n}=3\left(E\left[\sigma^{\infty}\right]=225 \mathrm{MPa}\right)$. 
the failure probabilities from all-weld and all-base analyses are slightly higher and lower, respectively, than those using both base and weld metal properties. The comparison with the corresponding deterministic results at $\sigma^{\infty}=225 \mathrm{MPa}$, shown in Fig. 6(a), supports this behavior. Finally, the failure probabilities from all three analyses are close to each other - a trend also supported by Fig. 6(a). Similar behavior is also reflected in the PDFs of $J$ obtained by all three analyses and are shown in Fig. 11(b). However, when the mean far-field tensile stress is raised to $450 \mathrm{MPa}$ (large), Fig. 12(a) and (b) show the corresponding results and an opposite trend is exhibited, consistent with deterministic observations in Fig. 6(a). Also, due to larger $\sigma^{\infty}$, the difference between the results calculated using all-base, all-weld, and base and weld metal properties increases and are shown in both failure probabilities and PDF of $J$.

For the case of $k_{\sigma}=2, k_{n}=3$, which represents a weld specimen overmatched with respect to strength, but undermatched with respect to material work hardening, Figs. 13 and 14 present the similar results of failure probability and PDF for mean far-field tensile stress of 450 (small) and $800 \mathrm{MPa}$ (large), respectively. They indicate a complete opposite behavior when compared with the results of Figs. 11 and 12. Similar

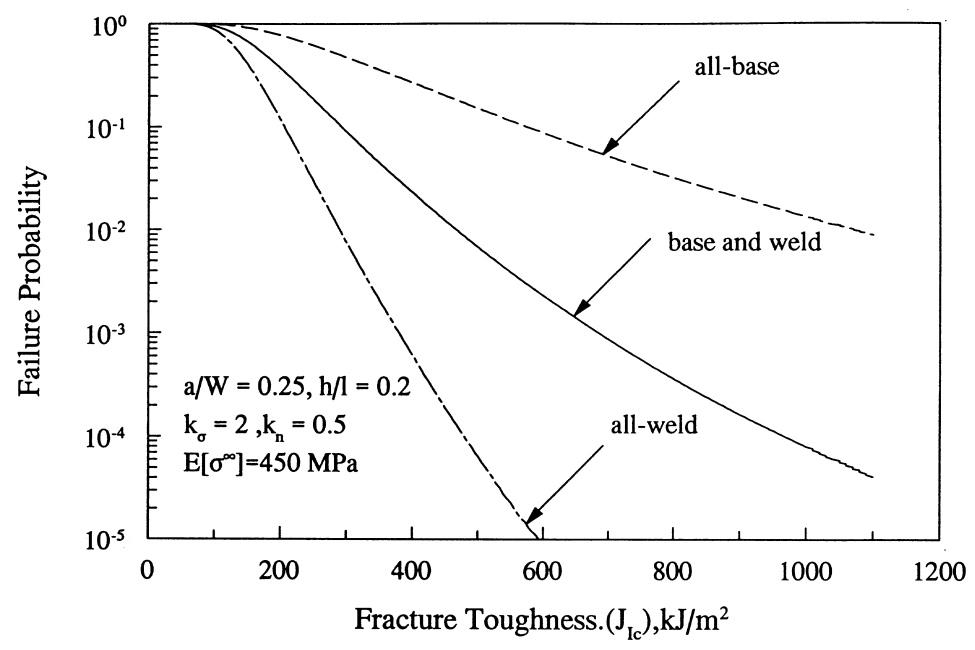

(a) Failure probability

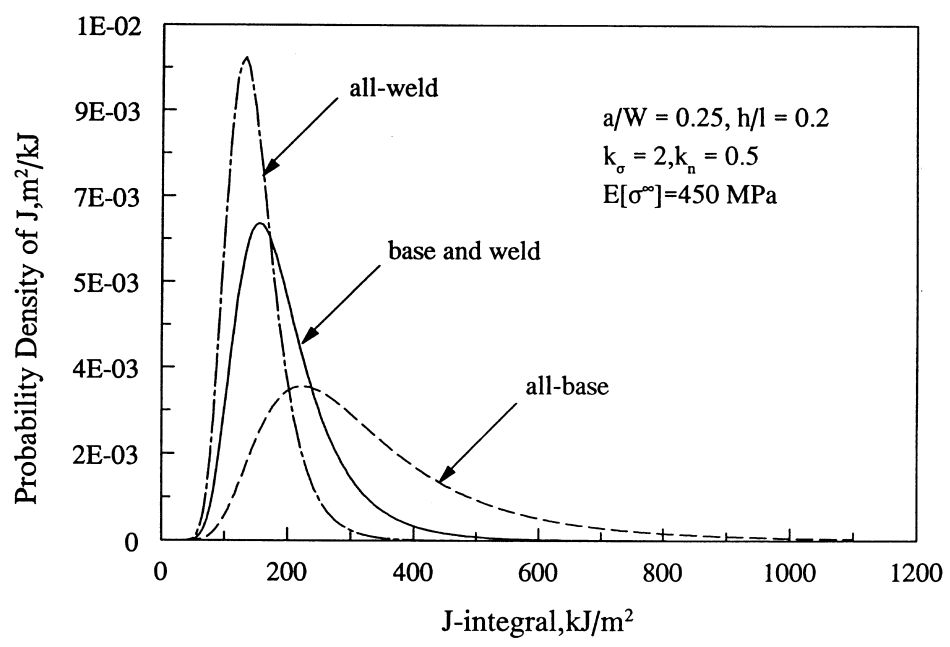

(b) PDF of J-integral

Fig. 16. Probabilistic results for $a / W=0.25, h / l=0.2, k_{\sigma}=2$, and $k_{n}=0.5\left(E\left[\sigma^{\infty}\right]=450 \mathrm{MPa}\right)$. 
trends were also found in the deterministic calculations of $J$ (see Fig. 6(d)).

Finally, Figs. 15 and 16 show the similar results of $P_{\mathrm{F}}$ and $\mathrm{PDF}$ of $J$ for the truly undermatched $\left(k_{\sigma}=0.5, k_{n}=3\right)$ and truly overmatched $\left(k_{\sigma}=2, k_{n}=\right.$ $0.5)$ welds, respectively. For the truly undermatched case, the failure probability is extremely high when only the tensile properties of weld are used. But, the calculations using material properties of both base and weld metals show that it is only slightly higher than those using all-base properties. A completely opposite behavior is shown for the truly overmatched welds. But, in this case, the failure probabilities calculated using both base and weld metals lie in the middle between the results of all-base and all-weld analyses.

\section{Summary and conclusions}

A methodology was developed for predicting probabilistic characteristics and failure probability of CCT weld specimens subject to far-field tensile stress. It is based on elastic-plastic analyses by ABAQUS to calculate $J$-integral, statistical models of uncertainties in loads and material properties, and standard computational methods of structural reliability theory for probabilistic analysis. Eighty-one deterministic FEAs were performed for a wide variety of crack size, material mismatch factors, and weld geometric parameters to develop approximate equations for the $J$-integral and were subsequently applied for probabilistic fracture evaluations. FORM/SORM and Monte Carlo methods were used to study the effects of mismatch factors on the failure probability. The results show that:

- The $J$-integral for a CCT weld specimen can be significantly affected by the mismatch factors on material strength and work-hardening parameters. Hence, tensile parameters of both base and weld materials should be accounted for when calculating $J$. This is the same conclusion reached by many researchers in the past.

- The material mismatch factors can significantly affect the prediction of failure probability and other probabilistic characteristics of $J$-integral. The failure probabilities can be predicted by FORM with a very good accuracy when compared with generally more accurate results of SORM and MCS.

- For truly undermatched and overmatched welds, the failure probabilities calculated by tensile properties of all-base, all-weld, base and weld metals can vary significantly.

- For mixed undermatching and overmatching welds, the failure probabilities calculated by tensile proper- ties of all-base, all-weld, base and weld metals strongly depend on the load intensity.

The authors are currently developing a similar probabilistic methodology for analyzing more realistic structures, such as pipe welds subject to bending, tension, torsion, and combined loads. The results will be published elsewhere.

\section{Acknowledgements}

The authors would like to thank Dr. Moe Khaleel and Dr. Fred Simonen of Pacific Northwest National Laboratory and Dr. David Harris of Engineering Mechanics Technology for their editorial corrections of an earlier version of this paper.

The work presented in this paper was supported by the Faculty Early Career Development Program of the US National Science Foundation (Grant No. CMS9833058). The program directors were Dr. Sunil Saigal and Dr. Ken Chong.

\section{Appendix A. A modified HL-RF method}

In FORM/SORM, the main effort is calculating the reliability index, $\beta_{\mathrm{HL}}=\left\|\mathbf{u}^{*}\right\|$, by finding the design point, $\mathbf{u}^{*}$, which can be formulated as a constrained optimization problem defined by

$$
\begin{aligned}
& \min _{\mathbf{u} \in \Re^{N}}\|\mathbf{u}\| \\
& \text { subject to } g_{U}(\boldsymbol{u})=0
\end{aligned}
$$

where $\mathfrak{R}^{N}$ is an $N$-dimensional real vector space, $\mathbf{u} \in$ $\mathfrak{R}^{N}$ is the space of standard Gaussian vector, $\mathbf{U} \in \mathfrak{R}^{N}$, and $g_{U}(\mathbf{u}): \mathfrak{R}^{N} \longmapsto \mathfrak{R}$ is the transformed performance function in u-space, and

$\|\mathbf{u}\| \stackrel{\text { def }}{=} \sqrt{\sum_{i=i}^{N} u_{i}^{2}}$

is the Euclidean $\mathscr{L}_{2}$-norm of the $\mathrm{N}$-dimensional vector, u. A modified HL-RF method, originally proposed by Hasofer and Lind [45] and later extended by Rackwitz and Fiessler [48] and modified by Liu and Kiureghian [62], is one of the most widely used and robust optimization methods to solve the reliability problem in Eq. (A1) $[46,62]$. The original HL-RF method involves an iterative algorithm given by the following recursive formula

$\mathbf{u}^{k+1}=\frac{1}{\left\|\nabla g_{U}\left(\mathbf{u}^{k}\right)\right\|^{2}}\left[\nabla g_{U}\left(\mathbf{u}^{k}\right)^{\mathrm{T}} \mathbf{u}^{k}-g_{U}\left(\mathbf{u}^{k}\right)\right] \nabla g_{U}(\mathbf{u})$ 
where, $\mathbf{u}^{k}$ is the vector at $k$ th iteration, $\nabla=$ $\left\{\partial / \partial u_{1}, \partial / \partial u_{2}, \ldots, \partial / \partial u_{N}\right\}^{\mathrm{T}}$ is a vector of gradient operators, and $\nabla g_{U}\left(\mathbf{u}^{k}\right)$ is the gradient of scalar field, $g_{U}\left(\mathbf{u}^{k}\right)$. The algorithm proceeds iteratively until convergence is achieved, i.e., when

$\left|u_{i}^{k+1}-u_{i}^{k}\right| \leq \varepsilon_{\mathrm{con}}, \quad$ for all $i$

and

$$
\left|g_{U}\left(\mathbf{u}^{*}\right)\right| \cong\left|g_{U}\left(\mathbf{u}^{k+1}\right)\right| \leq \varepsilon_{\text {con }}
$$

where $\varepsilon_{\text {con }}$ is a small control parameter assigned by the user. From the past experience of authors, a value of $\varepsilon_{\text {con }}=10^{-4}-10^{-3}$ usually yields satisfactory estimates of $\beta_{\mathrm{HL}}$.

To improve the robustness of Eq. (A3), Liu and Kiureghian proposed a non-negative merit function, $m\left(\mathbf{u}^{k}\right)$, which is defined as [62]

$m\left(\mathbf{u}^{k}\right)=\frac{1}{2}\left\|\mathbf{u}^{k}-\frac{\nabla g_{U}\left(\mathbf{u}^{k}\right)^{\mathrm{T}} \mathbf{u}^{k}}{\left\|\nabla g_{U}\left(\mathbf{u}^{k}\right)\right\|^{2}} \nabla g_{U}\left(\mathbf{u}^{k}\right)\right\|^{2}+\frac{1}{2} c g_{U}\left(\mathbf{u}^{k}\right)^{2}$

where, $c$ is some scalar positive constant. The merit function in Eq. (A6) is a convenient guide for selecting step size, since it is a function of quantities already known at the current iteration point, $\mathbf{u}^{k}$. This modification greatly improves the convergence (although not strictly guaranteed) of the original HL-RF method [62].

\section{References}

[1] Smith E. Comments on the problem of crack extension from a defect in a weld. Proceedings of 1991 ASME Pressure Vessels and Piping Conference. San Diego, CA. Bamford W, Meyer T, Wilkowski G, Rybicki E, Newaz G, Prager M, editors. Fatigue, fracture, and risk, PVPvol. 215. 1991, pp. 67-71.

[2] Nakagaki M, Marschall C, Brust FW. Analysis of cracks in stainless steel TIG welds. NUREG/CR-4806. US Nuclear Regulatory Commission, Washington, DC, December 1986.

[3] Nakagaki M, Marschall C, Brust FW. Elastic-plastic fracture mechanics evaluations of stainless steel tungsten/ inert-gas welds. In: Landes JD, Saxena A, Merkle JG, editors. ASTM STP 95. Philadelphia, PA: American Society for Testing and Materials, 1989. p. 214-43.

[4] Wilkowski G, Ahmad J, Brust F, Guerrieri Kramer G, Kulhowvick G, Landow M, Marschall C, Nakagaki M, Papaspyropoulos V, Scott P. Analysis of experiments on stainless steel flux welds. NUREG/CR-4878. US Nuclear Regulatory Commission, Washington, DC, April 1987.

[5] Rahman S, Wilkowski G, Brust F. Analysis of full-scale pipe fracture experiments on stainless steel flux welds.
Proceedings of 1994 ASME Pressure Vessels and Piping Conference. Minneapolis, MN. Wilkowski G, editors. Fatigue, flaw evaluation, and leak-before-break assessments-1994, PVP-vol. 280. 1994, pp. 255-72.

[6] Rahman S, Wilkowski G, Brust F. Fracture analysis of full-scale pipe fracture experiments on stainless steel flux welds. Nuclear Engineering and Design 1996;160:66-96.

[7] Gilles P, Franco C. A new $J$-estimation scheme for cracks in mis-matching welds - the ARAMIS method. In: Schwalbe M, Kocak KH, editors. Mismatching of welds. London: Mechanical Engineering Publications, 1994. p. 661-83.

[8] Eripret C, Hornet P. Prediction of overmatching effects on the fracture of stainless steel cracked welds. In: Schwalbe KH, Kocak M, editors. Mismatching of welds. London: Mechanical Engineering Publications, 1994. p. 685-708.

[9] Hornet P, Eripret C. Experimental $J$ evaluation from a load-displacement curve for homogeneous and overmatched SENB or CCT specimens. Fatigue and Fracture in Engineering Materials and Structures 1995;18(6):67992.

[10] Joch J, Ainsworth RA, Hyde TH. Limit load and $J$-estimates for idealized problems of deeply cracked welded joints in plane-strain bending and tension. Fatigue and Fracture in Engineering Materials and Structures 1993;16(16):1061-79.

[11] Wang YY, Kirk MT. Geometry effects on failure assessment diagrams. In: Proceedings of Second International Symposium on Mis-Matching of Welds, ReinstorfLuneburg, Germany. 1996.

[12] Lei Y, Ainsworth RA. A $J$-integral estimation method for cracks in welds with mismatched mechanical properties. International Journal of Pressure Vessels and Piping 1997;70:237-45.

[13] Lei Y, Ainsworth RA. The estimation of $J$ in threepoint-bend specimens with a crack in a mismatched weld. International Journal of Pressure Vessels and Piping 1997;70:247-57.

[14] Study on elastic-plastic fracture mechanics in inhomogeneous materials and structures. Final Report, prepared by EPI Subcommittee, Nuclear Engineering Research Committee, The Japan Welding Engineering Society, Principal Coordinator: Yagawa G, JWES-AE-9405, March 1994.

[15] Hornet P, Eripret C. Fracture behavior of circumferential through-wall-cracked welded pipes in four-point bending. Proceedings of 1997 ASME Pressure Vessels and Piping Conference. Orlando, FL. Rahman S, editors. Fatigue and fracture (Part II), PVP-vol. 346. 1997, pp. 317-24.

[16] Ganta BR, Ayres DJ. Analysis of cracked pipe weldments. EPRI Report No. NP-5057, Electric Power Research Institute, Palo Alto, February 1987.

[17] Rahman S, Brust F, Nakagaki M, Gilles P. An approximate method for estimating energy release rates of through-wall cracked pipe weldments. Proceedings of 1991 ASME Pressure Vessels and Piping Conference. San Diego, CA. Bamford W, Meyer T, Wilkowski G, Rybicki E, Newaz G, Prager M, editors. Fatigue, fracture, and risk, PVP-vol. 215. 1991, pp. 87-92. 
[18] Rahman S, Brust F. An estimation method for evaluating energy release rates of circumferential through-wall cracked pipe welds. Engineering Fracture Mechanics 1992;43(3):417-30.

[19] Rahman S, Brust F. Elastic-plastic fracture of circumferential through-wall cracked pipe welds subject to bending. Journal of Pressure Vessel Technology 1992;114(4):410-6.

[20] ABAQUS, User's guide and theoretical manual, Version 5.6. Hibbitt, Karlsson, and Sorensen, Pawtucket, RI, 1997.

[21] Rice JR. A path independent integral and the approximate analysis of strain concentration by notches and cracks. Journal of Applied Mechanics 1968;35:379-86.

[22] Hutchinson JW. Singular behavior at the end of a tensile crack in a hardening material. Journal Mech Phys Solids 1968;16:13-31.

[23] Rice JR, Rosengren GF. Plane strain deformations near a crack tip in a power-law hardening material. Journal Mech Phys Solids 1968;16:1-12.

[24] Atluri SN, Nishioka T, Nakagaki M. Incremental pathindependent integrals for inelastic and dynamic fracture mechanics. Engineering Fracture Mechanics 1984;20(2):209-44.

[25] Kishimoto K, Aoki S, Sakata M. On the path-independent integral $\hat{J}$. Engineering Fracture Mechanics 1980;13(2):841-50.

[26] Wilkowski GM et al. Degraded piping program - phase II. Final and Semiannual Reports, NUREG/CR-4082, vols. 1-8. US Nuclear Regulatory Commission, Washington, DC, 1985-1989.

[27] Wilkowski GM et al. Short cracks in piping and piping welds. Semiannual Reports, NUREG/CR-4599, vols. 14, Nos. 1 and 2. US Nuclear Regulatory Commission, Washington, DC, May 1991-January 1995.

[28] Schmidt RA, Wilkowski GW, Mayfield M. The international piping integrity research group (IPIRG) program - an overview. In: Proceedings of Eleventh International Conference on Structural Mechanics in Reactor Technology, Paper G23/1, August 1991. 1991.

[29] Hopper A, Mayfield M, Olson R, Scott P, Wilkowski G. Overview of the IPIRG-2 program - seismic loaded cracked pipe system experiments. In: Proceedings of Thirteenth International Conference on Structural Mechanics in Reactor Technology, Division F, Paper F12-1, August 1995. 1995.

[30] Rahman S, Olson R, Rosenfield A, Wilkowski G. Summary of results from the IPIRG-2 Round-Robin analyses. NUREG/CR-6337. US Nuclear Regulatory Commission, Washington, DC, February 1996.

[31] Brust F, Scott P, Rahman S, Ghadiali N, Kilinski T, Francini R, Krishnaswamy P, Wilkowski G. Assessment of short through-wall cracks in pipes - experiments and analyses. Topical Report, NUREG/CR-6235. US Nuclear Regulatory Commission, Washington, DC, April 1995.

[32] Krishnaswamy P, Scott P, Choi Y, Mohan R, Rahman S, Brust F, Wilkowski G. Fracture behavior of short circumferentially surface-cracked pipe. Topical Report, NUREG/CR-6298. US Nuclear Regulatory Commission, Washington, DC, November 1995.
[33] Scott P, Francini R, Rahman S, Rosenfield A, Wilkowski G. Fracture evaluations of fusion line cracks in nuclear pipe bimetallic welds. Topical Report, NUREG/CR-6297. US Nuclear Regulatory Commission, Washington, DC, April 1995.

[34] Hutchinson JW. Fundamentals of the phenomenological theory of nonlinear fracture mechanics. Journal of Applied Mechanics 1983;50:1042-51.

[35] Shih CF, Moran B, Nakamura T. Energy release rate along a three-dimensional crack front in a thermally stressed body. International Journal of Fracture 1986;30:79-102.

[36] Moran B, Shih CF. A general treatment of crack tip contour integrals. International Journal of Fracture 1987;35:295-310.

[37] Anderson TL. Fracture mechanics: fundamentals and applications, 2nd ed. Boca Raton, FL: CRC Press, 1995.

[38] Kumar V, German MD, Shih CF. An engineering approach for elastic-plastic fracture analysis. EPRI NP1931. Electric Power Research Institute, Palo Alto, CA, 1981.

[39] MSC/PATRAN, User's guide and theoretical manual, Version 7. The MacNeal-Schwendler Corporation, Los Angeles, CA, 1997.

[40] Francis M. Probabilistic analysis of weld cracks in center-cracked tension specimens. M.S. Thesis, Department of Mechanical Engineering, The University of Iowa, Iowa City, Iowa, August 1998.

[41] Rahman S, Francis M. Probabilistic analysis of weld cracks in center-cracked tension specimens. In: Proceedings of 1998 ASME/JSME Joint Pressure Vessels and Piping Conference, San Diego, CA. 1998.

[42] Rahman S. A stochastic model for elastic-plastic fracture analysis of circumferential through-wall-cracked pipes subject to bending. Engineering Fracture Mechanics 1995;52(2):265-88.

[43] Rahman S. Probabilistic fracture analysis of pipes with circumferential flaws. International Journal of Piping and Pressure Vessels 1997;70:223-36.

[44] Rahman S, Brust FW. Probabilistic elastic-plastic fracture analysis of cracked pipes with circumferential through-wall flaws. In: Proceedings of the 1995 ASME/ JSME 1995 Pressure Vessel and Piping Conference, Honolulu, Hawaii. 1995.

[45] Hasofer AM, Lind NC. An exact and invariant firstorder reliability format. Journal of Engineering Mechanics 1974;100:111-21.

[46] Madsen HO, Krenk S, Lind NC. Methods of structural safety. Englewood Cliffs, NJ: Prentice-Hall, 1986.

[47] Haldar A, Mahadevan S. First-order and second-order reliability methods. In: Sundararajan C, editor. Probabilistic structural mechanics handbook - theory and applications. New York, NY: Chapman and Hall, 1995.

[48] Rackwitz R, Fiessler B. Structural reliability under combined random load sequence. Computers and Structures 1978;9:489-94.

[49] Chen X, Lind NC. A new method for fast probability integration. University of Waterloo Research Report, No. 171, Waterloo, Canada, 1982. 
[50] Ditlevsen O. Generalized second moment reliability index. Journal of Structural Mechanics 1979;7(4): 435-51.

[51] Ditlevsen O. Narrow reliability bounds for structural systems. Journal of Structural Mechanics 1979;7(4): 453-72.

[52] Fiessler B, Nuemann HJ, Rackwitz R. Quadratic limit states in structural reliability. ASCE Journal of Engineering Mechanics 1979;105(4):661-76.

[53] Breitung K. Asymptotic approximations for multinormal integrals. ASCE Journal of Engineering Mechanics 1984;110(3):357-66.

[54] Hohenbichler M, Gollwitzer S, Kruse W, Rackwitz R. New light on first- and second-order reliability methods. Structural Safety 1987;4:267-84.

[55] Tvedt L. Two second-order approximations to the failure probability. Det Norske Veritas Technical Report, No. RDIV/20-004-83, Hovik, Norway.

[56] Tvedt L. Distribution of quadratic forms in normal space - application to structural reliability. ASCE Journal of Engineering Mechanics 1990;116(6):1183-97.
[57] Der Kiureghian A, Lin HZ, Hwang SF. Second-order reliability approximations. ASCE Journal of Engineering Mechanics 1987;113(8):1208-25.

[58] Breitung K. Probability approximations by loglikelihood maximization. Seminar fur angewandte stochastik. In: Seric Sto Nr. 6, Institute fur Statistic and Wissenschaftstheoric, University of Munich, Munich, Germany. 1989.

[59] Der Kiureghian A, Liu P-L. Structural reliability under incomplete probability information. ASCE Journal of Engineering Mechanics 1986;112(1):85-104.

[60] Rubinstein RY. Simulation and the Monte Carlo method. New York, NY: Wiley, 1981.

[61] Rahman S, Ghadiali N, Paul D, Wilkowski G. Probabilistic pipe fracture evaluations for leak-rate-detection applications. NUREG/CR-6004. US Nuclear Regulatory Commission, Washington, DC, April 1995.

[62] Liu PL, Kiureghian AD. Optimization algorithms for structural reliability. Structural Safety 1991;9:161-77. 